Dynamics of the UK Natural Gas Industry: System Dynamics Modelling and Long-Term Energy Policy Analysis

Kong Chyong Chi, David M. Reiner and William J. Nuttall

June 2009

CWPE 0922 \& EPRG 0913 


\title{
DYNAMICS OF THE UK NATURAL GAS INDUSTRY: SYSTEM DYNAMICS MODELLING AND LONG-TERM ENERGY POLICY ANALYSIS
}

\author{
EPRG Working Paper 0913 \\ Cambridge Working Paper in Economics 0922
}

\section{Kong Chyong Chi , David M. Reiner and William J. Nuttall}

The UK offshore natural gas and oil industry has a long and successful history and has been said to represent the pride of UK engineering science. For over 30 years, the North Sea has provided the UK with a reliable and flexible source of gas that has greatly benefited the UK, but as gas reserves, and consequently production, decline the UK will rely increasingly on imports.

Usually, equilibrium is the principal goal of economic analysis. Nevertheless, sometimes policy makers are interested not only in equilibrium predictions arising from traditional economic models but also in the trajectory taken by policy variables as these variables approach that equilibrium. System dynamics (SD) modelling approach has been extensively applied for cases in which energy systems are in transition. Thus, the SD approach is in a good position to analyze systems which are in disequilibrium caused by structural shifts such as the decline in UK indigenous gas production.

The SD approach is consistent with traditional economic modelling of dynamic phenomena, but employs different terminology and conventions. From a mathematical point of view, the relationships between system variables could be modelled using systems of ordinary differential equations. With advances in software technology, such models can be readily constructed and various alternative model specifications tested. We use the system dynamics (SD) approach to investigate the factors influencing the long-term rate of UK indigenous natural gas production and to determine the nature of system behaviour as well as to examine the effectiveness of various policies in softening the transition from self-sufficiency to gas import-dependence in the long- 


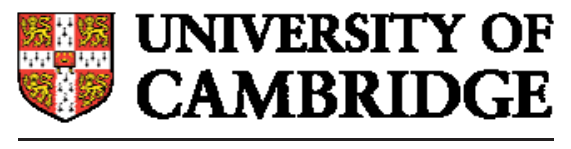

Electricity Policy

Research Group

term. The key insights from our SD model are derived from the integration of econometric estimations, which yields numerical estimations of the trajectories of key policy variables, as well as any equilibria to which they might converge.

In particular, we found that supply-side policy alone cannot substantially postpone the discovery, production and consumption peaks. One might expect that a low taxation policy would encourage more exploration and production of gas and thereby stimulate higher consumption rates. Instead, there was no overall net effect on production and consumption in the long term. The depletion effect on the cost of exploration acts as a counterbalance to low taxation policy. Depletion translates into rising costs and prices, which depresses consumption. The advances in exploration and production technology can delay the peak of exploration, production and consumption. Technological improvements mean lower cost of exploration and production which exert downward pressure on the long-term pattern of price dynamics. We also found that the dynamics of the main variables, namely, exploration, production and consumption, are sensitive to initial demand conditions. Postponing the onset of natural gas price increases can therefore be achieved more effectively through efforts to reduce demand growth. Analysis of alternative policies indicates that the most effective policies for prolonging indigenous gas production and consumption are those that combines both supply and demand side measures.

Contact

Publication

Financial Support k.chyong@jbs.cam.ac.uk

May 2009

ESRC Electricity Policy Research Group 


\title{
DYNAMICS OF THE UK NATURAL GAS \\ INDUSTRY: SYSTEM DYNAMICS MODELLING AND LONG-TERM ENERGY POLICY ANALYSIS
}

\author{
EPRG Working Paper 0913
}

Cambridge Working Paper in Economics 0922

\section{Kong Chyong Chi, David M. Reiner and William J. Nuttall}

Abstract

Keywords
We present a dynamic model of the indigenous natural gas industry in the UK. The model has been built using a system dynamics approach. Using the model several scenarios have been analysed. We found that management of the supply-side policy alone cannot substantially postpone the discovery, production and consumption peak. We also found that the dynamics of the main variables, namely, exploration, production and consumption, are sensitive to initial demand conditions. Postponing the onset of gas price increases can therefore be achieved more effectively through efforts to reduce demand growth. One might expect that a low taxation policy would encourage more exploration and production of gas and thereby stimulate higher consumption rates. Instead, there was no overall net effect on production and consumption in the long term. The depletion effect on cost of exploration acts as counterbalance to low taxation policy. Depletion effect causes cost and thus price to rise further which depress consumption rate. The advances in exploration and production technology can delay the peak of exploration, production and consumption. Technological improvements mean lower cost of exploration and production which pressure down long-term pattern of price dynamics.

\footnotetext{
System Dynamics; Simulation Modelling; natural gas; energy policy; long-term policy analysis;
} 


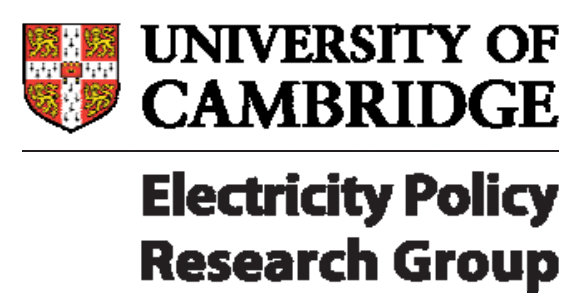

JEL Classification Q48; C63; Q41

Contact

Publication

Financial Support k.chyong@jbs.cam.ac.uk May 2009

ESRC Electricity Policy Research Group 


\title{
DYNAMICS OF THE UK NATURAL GAS INDUSTRY: SYSTEM DYNAMICS MODELLING AND LONG-TERM ENERGY POLICY ANALYSIS
}

\author{
Kong Chyong Chi* \\ David M. Reiner ${ }^{\dagger}$ \\ and \\ William J. Nuttall ${ }^{\ddagger}$
}

\footnotetext{
* PhD Student, Judge Business School, University of Cambridge, k.chyong@jbs.cam.ac.uk (contact author)

${ }^{\dagger}$ Senior Lecturer in Technology Policy and Course Director of the MPhil in Technology Policy at Judge Business School, University of Cambridge, dmr40@cam.ac.uk

¥ Senior Lecturer in Technology Policy at Judge Business School, University of Cambridge, wjn21@,cam.ac.uk
} 


\section{Introduction}

The UK offshore natural gas and oil industry has a long and successful history and has been said to represent the pride of UK engineering science (Wright, 2006). For over 30 years, the North Sea has provided the UK with a reliable and flexible source of gas that has greatly benefited the UK, but as gas reserves, and consequently production, decline the UK will rely increasingly on imports (DTI, 2006a).

Usually equilibrium is the principal goal of economic analysis. Nevertheless, sometimes policy makers are interested not only in equilibrium predictions arising from traditional economic models but also in the trajectory taken by policy variables as these variables approach that equilibrium. As will be shown later in the literature review, most system dynamics (SD) energy models have been applied in cases where energy systems are in transition. Thus, we take the view that SD approach is in a good position to analyze systems which are in disequilibrium caused by structural shifts such as a decline in UK indigenous gas production.

The SD approach is consistent with traditional economic modelling of dynamic phenomena, but employs different terminology and conventions. The primary focus of the SD approach is on the feedback structure of the system under analysis. The representation of the feedback structure is usually done using causal loop diagrams (CLD). The feedback could be either balancing, which capture negative feedback, or reinforcing, which captures positive feedback. A balancing feedback exhibits goal-seeking behaviour, under which the system seeks to return to equilibrium after a disturbance occurred in the system. Such behaviour conforms to the economic description of a stable equilibrium. By contrast, a reinforcing loop (negative feedback) represents a situation when an initial disturbance leads to further changes in the system. This kind of systems behaviour suggests the presence of an unstable equilibrium.

The systems structure is formalised using a simulation model consisting of a network of two elements: stocks and flows. The inertia of the system is captured by the stocks. Stocks either accumulate or deplete gradually. The rate of changes in stocks is regulated by stocks' in- and out-flows. Stocks can be both tangible (e.g. proven gas reserves) and intangible (e.g. perceptions) concepts. The flow rates depend on various factors such as level of stocks in the system or exogenous parameters. These flow rates can be interpreted, for example, as output or input of policies, i.e. a decision making process. For example, in our paper, stock represents proven gas reserves and in-flow of that stock is discovery rate of natural gas while out-flow is gas production rate.

From mathematical point of view, the relationships between systems' variables could be modelled using systems of ordinary or differential equations. With the advancements in software technology such models could be readily constructed and various alternative model specifications could be tested. In particular, using system dynamics (SD) approach we investigate the factors influencing the long-term rate of UK indigenous natural gas production and to determine the nature of system behaviour as well as examining the effectiveness of various policies in softening the transition from self-sufficiency to gas import-dependence in the long-term. Furthermore every assumption regarding functional relationships 
between variables of our model was verified using econometric analysis. The key insight from our SD model with integration of econometric estimations is that the model yields numerical estimations of the trajectories of key policy variables, as well as any equilibrium to which they might converge.

The paper is organised as follows: in the next section the state of the literature on SD energy modelling is reviewed. Section 3 introduces the model assumptions. Section 4 presents the model's structure and its general description. In section 5, the dynamic behaviour of the model and its validation can be found. Section 6 presents the results of alternative scenarios and section 7 discusses the major conclusions that can be drawn from our analysis.

\section{State of the Literature}

The application of system dynamics modelling to energy resources began in 1970s. One of the first extensive SD energy models, COAL2, was developed for the U.S. government (Naill 1977; 1992; Naill et al. 1992). The COAL2 model served as a basis for another large-scale SD energy model, FOSSIL2, which has played an important role in U.S. energy planning since the late 1970s. Apart from these two extensive models, the SD approach has been applied to other issues related to the US energy system, such as conservation (Ford and Bull 1989), policy evaluation (Ford 1983), investment and uncertainty (Ford 1985), and power plant construction cycles in the competitive US electricity market (Ford 1999). In the early 2000s, Ford (2000) applied the SD approach to construct a model for the California Energy Commission that explored patterns of power plant construction that could arise from different theories of investor behaviour. Other large scale SD energy models include Sterman's (1983) model of energyeconomy interactions, the Geraghty and Lyneis (1985) model which assessed the effects of external agents on utility performance, and the Davidsen et al. (1990) model of the petroleum life-cycle.

Outside the U.S., SD energy models have been developed for the European energy industry including a model of inter-fuel substitution applied to OECD countries (Moxness 1990). An application of an SD energy model for France was done by Roche (1989). SD modelling approach of the energy sector has also applied to other countries including: Argentina (Rego, 1989), Colombia (Dyner, Smith and Pena, 1993), India (Chowdhurg and Sahu, 1992), and New Zealand (Bodger and May, 1992).

For the UK energy system specifically, numerous SD models were developed during the 1980s and 1990s. For example, a series of SD energy models were developed to investigate the issues related to privatisation of UK gas and electricity industries (Bunn and Larsen 1992; 1994; Bunn, Larsen and Vlakos 1993). In the late 1990s, another SD energy model was built to analyze the market power of dominant players in UK gas and electricity market (Bunn, Dyner and Larsen 1997).

The model used in this paper builds on Naill (1973) and Sterman et al. (1983). However, our model has substantially broadened the representation of the gas industry beyond that found in Naill's model (1973). In particular, we have tried to tackle some of the limitations which, in our opinion, made Naill's model (1973) a less realistic representation for the specific case of indigenous UK gas production. 
Firstly, the structure of Naill's model (1973) implies that production rate equals usage rate, modified by price. We find this assumption to be unrealistic in our case and therefore we explicitly model the production process.

Secondly, Naill (1973) modelled the potential demand exogenously assuming a constant growth rate. We take an approach similar to Sterman et al. (1983), and model the gas demand through substitution effects on one side and exogenous growth of total primary energy demand on the other side.

Thirdly, Naill (1973) did not model inter-fuel substitution which is an important issue for long-term energy modelling. Naill (1973) suggested that the assumption of independence, particularly between oil and gas, could affect the specific behaviour of the model in the early stages of gas discovery but would not affect overall model behaviour. The justification given for ignoring the oil and gas interdependency was that at that time in the U.S. over $70 \%$ of all gas wells were unassociated with oil (Adelman, 1962). Sterman et al. (1983) did include substitution between gas and oil in their model and we follow approach and model inter-fuel substitution explicitly.

Lastly, both Naill (1973) and Sterman et al. (1983) have pointed out that the outcome of investment in exploration is generally not known for perhaps four to five years because of the need to wait for the results of site drilling, accurate resource estimation, etc. Therefore gas producers must inevitably base their exploration-related investment decisions on demand and price projections. However in Naill's model (1973), the determinant of discovery rate is production or usage rate, which represents the current rather than the projected rates. Accordingly, the exploration-related investment decisions in our model are based on information about future demand.

\section{Model assumptions}

Since we are interested in overall system behaviour the model assumes that the UK gas industry has only one firm exploring and producing an undifferentiated product, natural gas. This assumption is similar to that used by Naill (1973) and by Sterman et al. (1983).

The model has a uniform price for natural gas driven by supply-demand conditions, but we will focus here specifically on the wholesale price. By the average wholesale price we mean average wellhead price plus the costs of conveying to the UK beach and the costs of treatment. In reality, there is no single price for natural gas and the gas price issue is very complicated (Wright, 2006). We are not conducting a detailed investigation into the nature of different gas prices so when we discuss gas price we mean the average wholesale price, which roughly corresponds to the UK OTC wholesale price. The use of the wholesale price as the proxy for the commodity gas price in the UK might be justified since Wright (2006) found that there are significant positive correlations in gas prices in the UK.

The model does not consider potential effects of imports or exports on system behaviours. Also the model does not explicitly model technological improvements in exploration or production. However the 
effects of technological improvements can be analyzed in our model by assuming that unit costs of exploration and production fall over time.

\section{Model structure and general description}

The model consists of three main parts, namely exploration sector, production and consumption sector, demand and substitution sector.

\subsection{Exploration sector}

The exploration sector is mainly represented by three negative feedback (balancing) loops (for details of main loops and their variables see appendix A). These loops represent the relationships between discovery rate, costs, investment and demand (Figure 1).

Undiscovered reserves (UR) is the total volume of natural gas expected to be found in the future that is not due to growth of existing fields. It assumes current discovery technologies and is not necessarily economically exploited (USNPC, 2003). We follow Hubbert's (1956) assumption that the amount of fossil fuels, in our case natural gas, is finite. This assumption is more accurate for a wellexplored mature basin such as the UK sector of the North Sea. Proved reserves (PR) are defined as those reserves that have a high confidence of being produced, and by implication, that are already economic. The data for UR and PR were derived from the UK Department of Trade and Industry's annual Energy Reports 1998-2001 (The "Brown Book”) (DTI, 2007) and the UK energy sector indicators 2006 (DTI, 2006b).

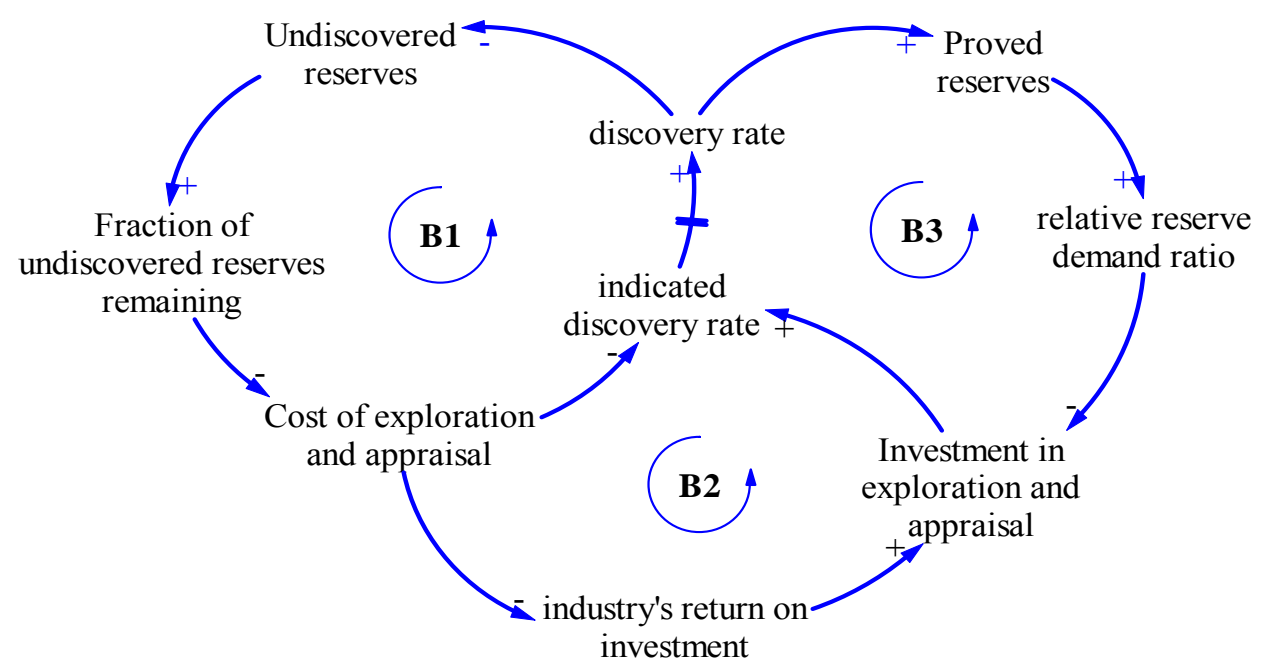

Figure 1: Causal loop diagram of Exploration sector

The key assumption here is that a fall in the fraction of undiscovered reserves remaining (FURR) will cause the cost of exploration and appraisal (COE\&A) drilling to increase. To test this assumption a regression was performed on 1987-1998 data for COE\&A drilling and FURR. The result of regression is reported in appendix B. A functional relationship as indicated by (B.1) could be represented through a multiplier (COE\&AM) as in figure 2. 


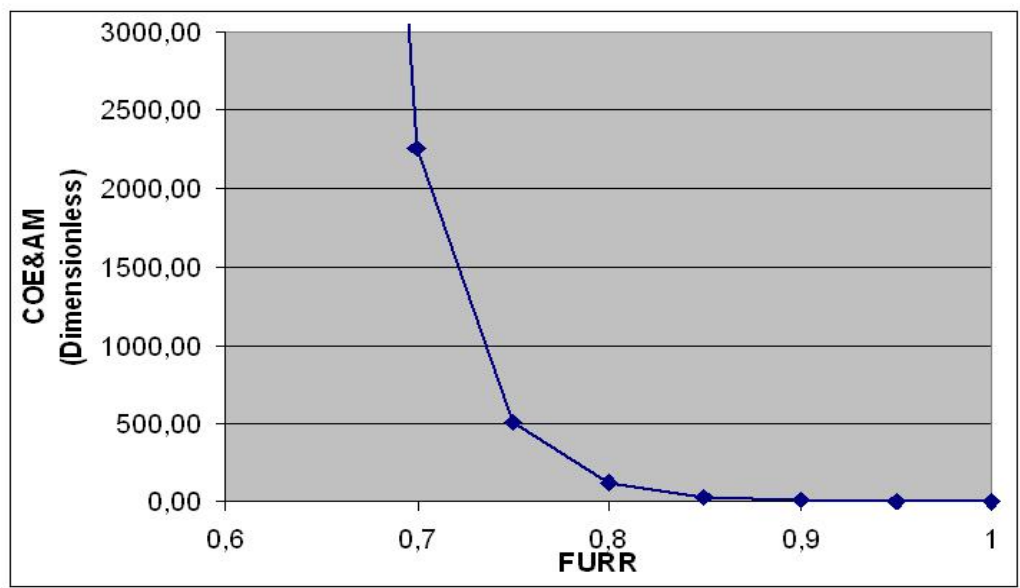

Figure 2: Relationship between FURR and COE\&AM

The relationship reflects the fact that there are diminishing marginal returns from a gas field. The fact that when variable FURR approaches the value of 0.7 the multiplier COE\&AM tend to infinity reflects UK's rapid depletion policy of oil and gas resources of UKCS.

The data for COE\&A drilling is difficult to obtain because of the allocation problem between oil and gas exploration and appraisal (E\&A) drilling. The DTI "Brown Book" (DTI, 2007) reported the data on capital investment which included the total cost of exploration and appraisal drilling for oil and gas wells. To derive the cost of gas E\&A drilling alone we have calculated the share of successfully drilled gas wells against oil wells. This share gave us an approximation of investment that went on gas E\&A. The methodology for calculating COE\&A employed in this study is similar to that of Naill (1973). Consequently, the annual amount of gas discoveries (Indicated discovery rate or 'IDR') is defined as industry's total investment in E\&A drilling divided by the COE\&A in GBP per cubic meter of gas discovered (appendix B, eqn. B.4).

We model the discovery rate (B.5) with a lag of 4.5 years which is the leadtime between initial date of investment in E\&A drilling and commencement of field development. For example Kemp and Kasim (2003) using extensive econometric model of UKCS oil and gas activities obtained a result of 1.8 year between gas discoveries and field development. It should be noted that the value of 1.8 year obtained by Kemp and Kasim (2003) might be underestimated as the authors themselves noted that: "...higher average leadtime are to be expected when the investment dates of other discoveries are determined" (Kemp and Kasim, 2003). The delay value of 4.5 years is also consistent with early estimates from Khazoom (1971) who derived the value on the basis of regression analysis of the response of gas discoveries to changes in gas price. His results suggest that the delay between E\&A investments and actual discoveries is 4.5 years.

Industry's total investment in new exploration activities is assumed to be proportional to its sales revenue. During the industry's growth phase this enables its further expansion through higher rate of investment in new gas discoveries. Like any type of investment decision, the decision to invest in E\&A depends on industry's return on investment (ROI, loop B2) and the relative reserve-demand ratio (RRDR, 
loop B3). This assumption is consistent with results yielded from regressions (equations B.6 and B.7 in appendix B) performed on data for industry's ROI, RRDR and percentage of sales invested in E\&A (PSIE\&A).

Regression results (eqn. B.6 in appendix B) show that the relationship between PSIE\&A and RRDR is negative. Producers will invest in exploration of new fields only if they expect that demand would exceed some 'normal' level. If the RDR falls below the 'normal' level, which is assumed to be 10 years in our model (based on industry's historical data taken from (BP, 2007) producers will invest more to satisfy growing demand. By contrast, a fall in projected demand would cause RDR to exceed the desired level, which in turn discourages investment.

Regressions performed on ROI and PSIE\&A data (eqn. B.7 in appendix B) yielded a positive coefficient, which verifies our assumption that investment in E\&A is driven by dynamics of ROI as well. To incorporate these findings in our model, PSIE\&A has been modelled as the product of the ROI Factor and RRDR Factor (Figure 3 and 4). RRDRF and ROIF curves were derived from (B.6) and (B.7).

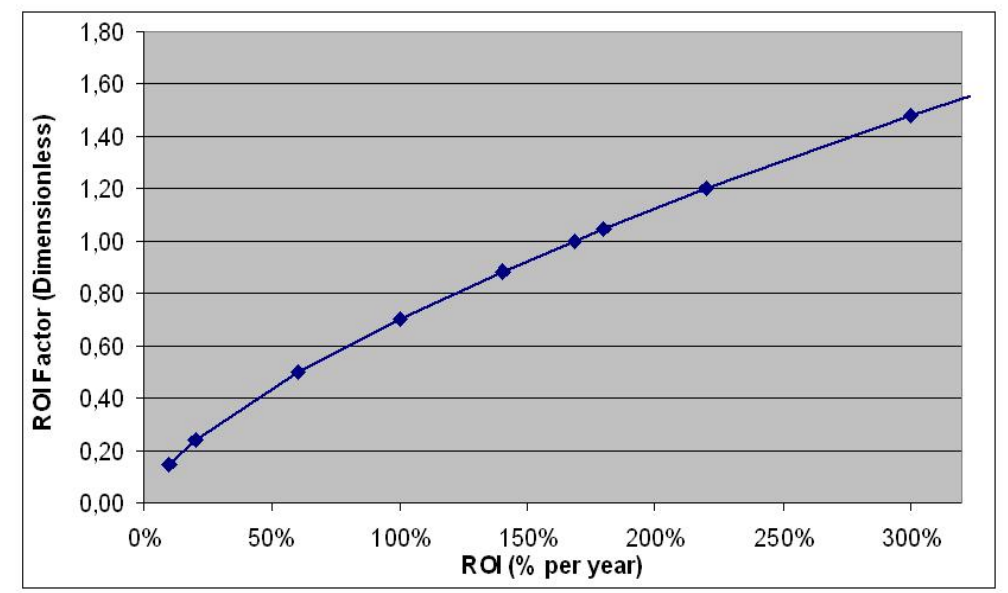

Figure 3: ROI versus ROI Factor

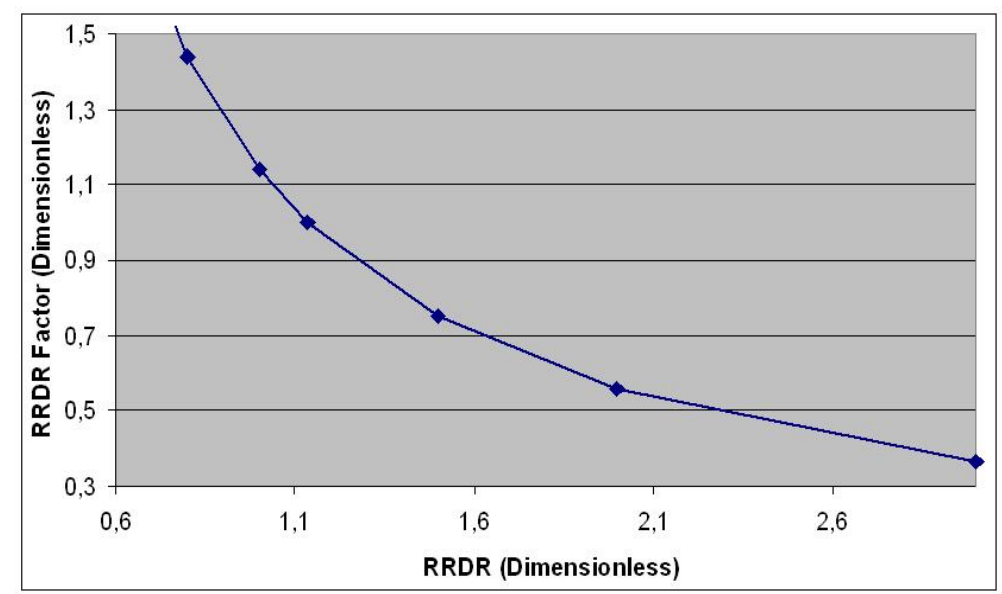

Figure 4: RRDR versus RRDR Factor

These two mechanisms (figures 3 and 4) imply that investment in E\&A will be encouraged when (i) the proved reserves are not anticipated to be large enough to cover projected demand and (ii) ROI is 
high enough; by contrast, these mechanisms discourage investment when (i) proved reserves are much larger than projected demand or (ii) ROI is relatively low.

\subsection{Production and consumption sector}

The production rate is determined by two main forces: (i) industry's willingness to invest in production (loop B4); and (ii) the consumption rate (loop B5) (see figure 5). Basically, the loop B4 represents the supply side (production side). The consumption rate is determined by the price of natural gas and demand (loop B5).

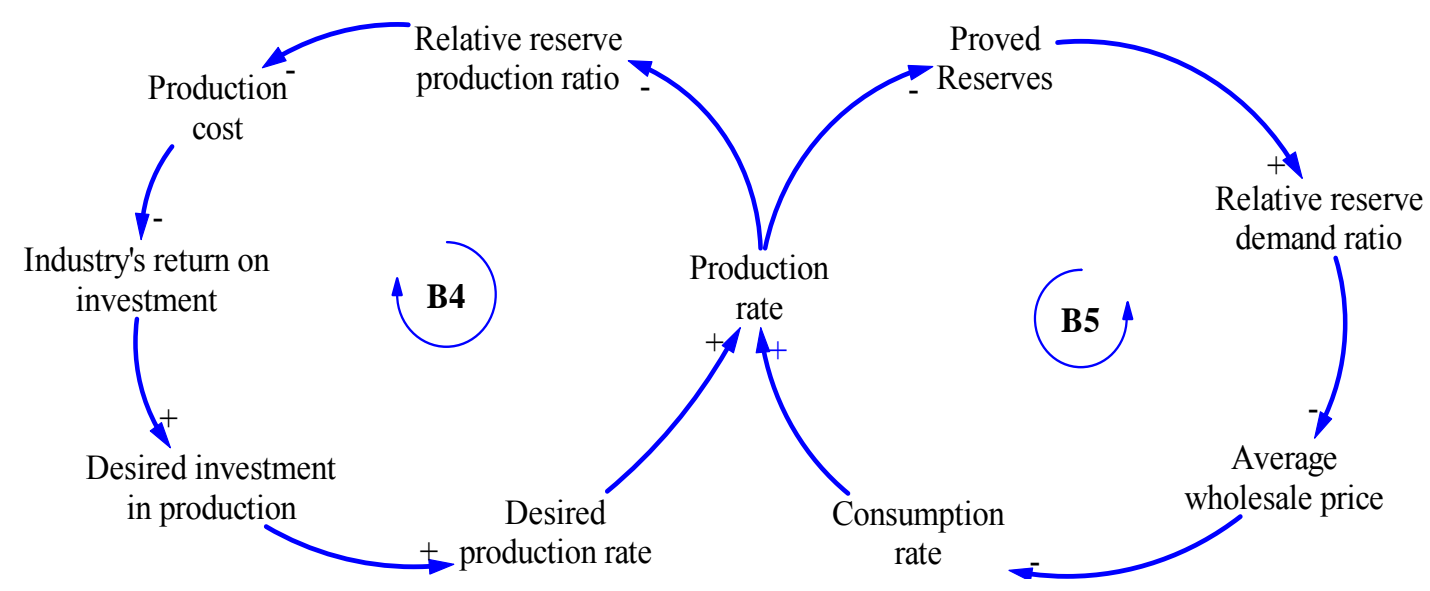

Figure 5: Causal Loop diagram of production and consumption sector

The loop B4 shows that an increase in production rate causes the relative reserve-production ratio (RRPR) to rise and an increase in RRPR causes the Production Unit Cost (PUC) to rise. A rise in the PUC will ensure that the production rate will be lower than it otherwise would have been.

The main assumption of the loop B4 is that when RPR exceeds its "normal" value, the PUC tends to increase. The production rate from a reservoir can be increased by drilling additional production wells, but well numbers are limited by their cost compared with the extra flow rate (Posner et al. 1981). Another limitation on useful investment in producing wells is the well density i.e. there can be technological limits to the number of producing wells that can be installed for a given field (Sterman et al. 1983). The NRPR is assumed to be 12 years, which corresponds to the industry average (Posner et al. 1981). Therefore, as production rate increases and proved reserves are depleted, the RPR approaches its normal value, in order to extract more gas additional wells and other facilities will need to be installed. The functional relationship between the depletion of gas reserves and PUC was obtained using a regression analysis. Equations (B.12-B.14) in appendix B highlight regression results.

Based on the results of (B.12 in appendix B) the Production Cost Factor (PCF) curve was derived by normalising its value to 1.0 at the 1987 level of RRDR (1.22). The PCF curve versus RRPR is represented in figure 6. 


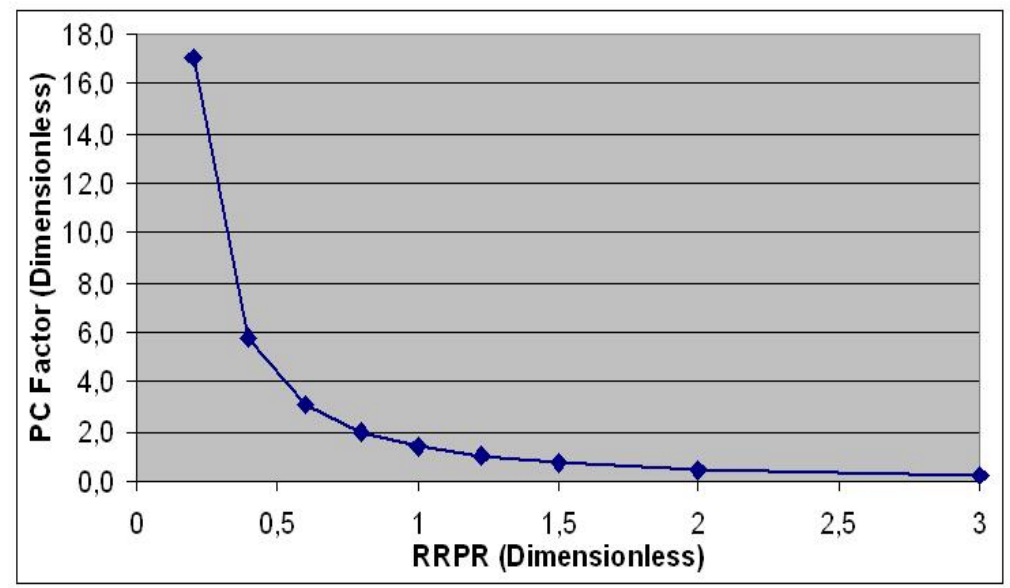

Figure 6: RRPR versus PC Factor

As in the case for E\&A investment (loop B2), the model assumes that the percentage of sales revenue invested in production (PSIP) depends on the dynamics of industry's ROI. This assumption is verified against the results of the regression (eqn. B.15 in appendix B) performed on data for operating expenditures plus other costs related to production expansion and actual ROI (DTI, 2007).

The relationship between ROI and PSIP Factor (PSIPF) is shown in Figure 7. The PSIPF curve was derived from (B.15) by normalising its value to 1.0 at 1987 levels (168\% ROI).

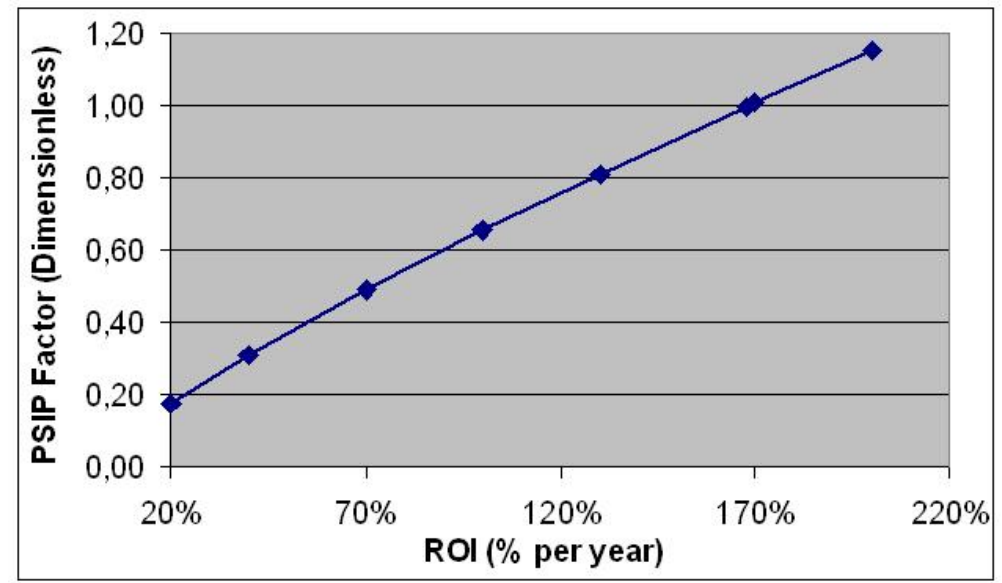

Figure 7: ROI versus PSIPF

The impact of producers' willingness to expand gas production on the actual production rate is seen in the variable, Desired Production Rate (DPR). This variable represents the producers' desired annual output based on information regarding ROI. The calculation of DPR is shown in (B.16) and (B.17).

The relationships between reserves, price, consumption and production rate are represented through loop B5. The loop works in the following way: an increase in the production rate depresses proved reserves, which in turn leads to a decrease in RRDR. The decrease in RRDR causes the gas price to rise, which in turn decreases the consumption rate. As a result, the production rate will be lower than it otherwise would have been. The main assumptions of this loop are: (i) the gas price is determined through the variable RRDR and (ii) gas consumption is price sensitive. 
The assumption that the price depends on projected demand and availability of gas reserves is consistent with the results of the ILEX report on gas prices in the UK (ILEX, 2004). ILEX (2004) reported that apart from linkages to oil price, gas prices in the UK are driven by demand-supply balancing as well as market sentiment (expectations of market players about future demand/supply). To check the assumption a regression was performed on data for gas price and variable RRDR (Earp, 2007; DTI, 2007). The result of the regression (eqn. B.18 in appendix B) confirms our assumption.

So in our model, the average wholesale price (AWP) of natural gas is determined to be a product of the total unit cost (TUC) and the price factor (PF) which is influenced by the RRDR dynamics (Figure 8). PF curve was derived from (B.18). Formally, the price (AWP) is defined as indicated in (B.19-B.21).

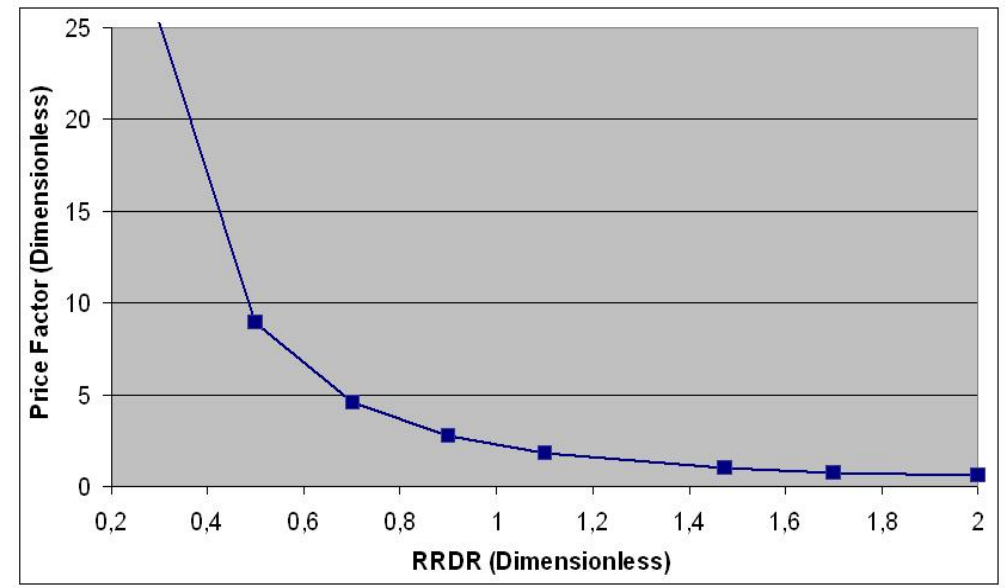

Figure 8: RRDR versus PF

The assumption that gas consumption is price sensitive is supported by analysis of long-term electricity consumption and prices in the UK (Figure 9). In 2005, natural gas contributed 29\% of electricity generation in the UK (DTI, 2007); thus, if the gas price increased electricity generators would be expected to switch to other fuels (e.g. coal). In 2004, coal prices rose relative to gas prices which led to a reduction in the amount of coal consumed. Similarly, the large increases in gas prices in 2005 and 2006 meant that more coal was used for generation than gas (BERR, 2007a). 


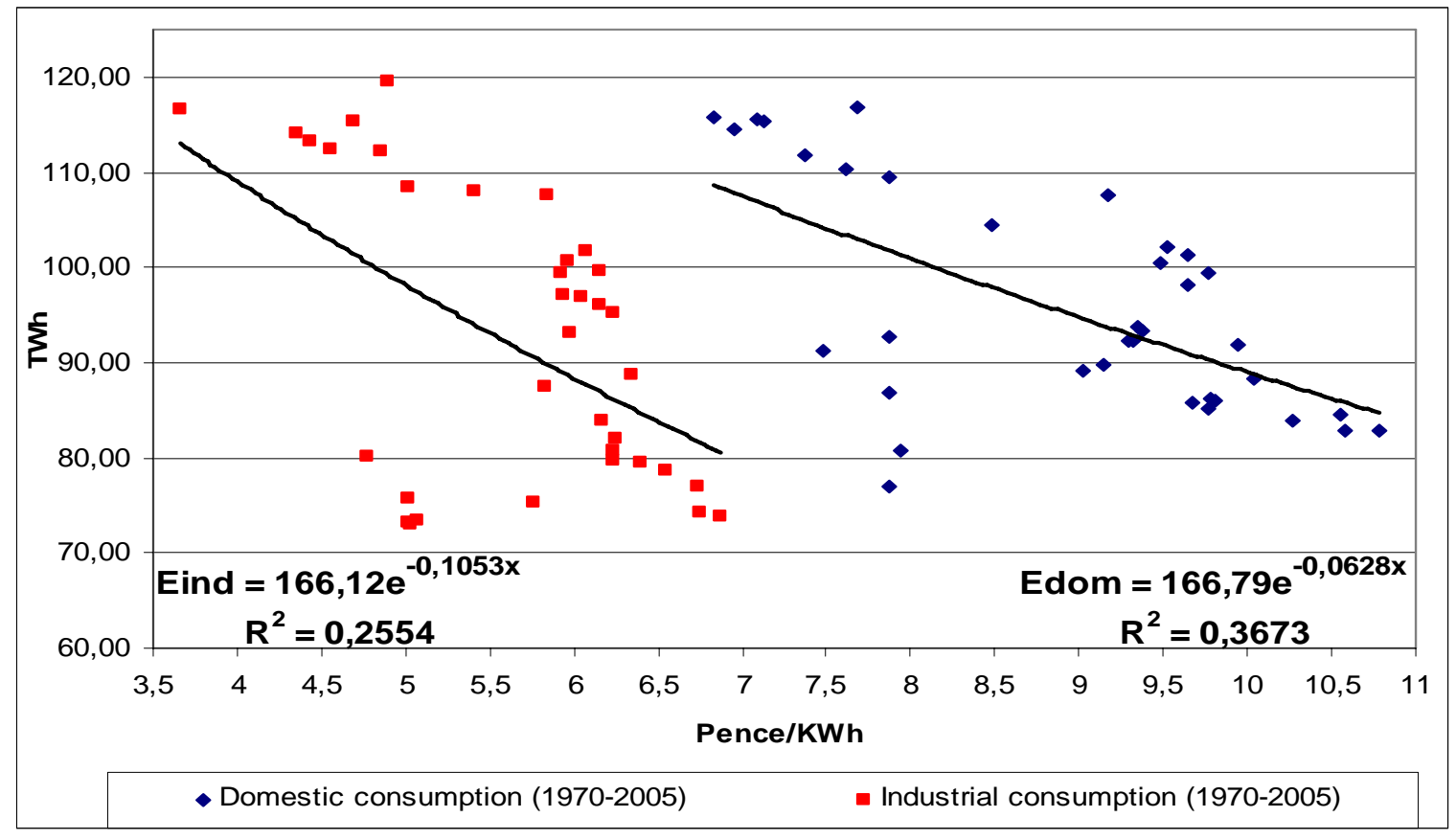

Figure 9: Electricity price and consumption in the UK 1970-2005*

This assumption is validated by results of regression performed on data for average gas price and consumption rate in UK in the period 1987-2005. The result of this regression analysis is reported in the appendix B (eqn. B.22). The regression (eqn. B.22) finds a negative price coefficient and that there is a significant relationship, therefore, we can assume that natural gas consumption is price sensitive. The relationship between gas price and actual consumption can be represented through the Consumption Factor (CF) (Figure 10).

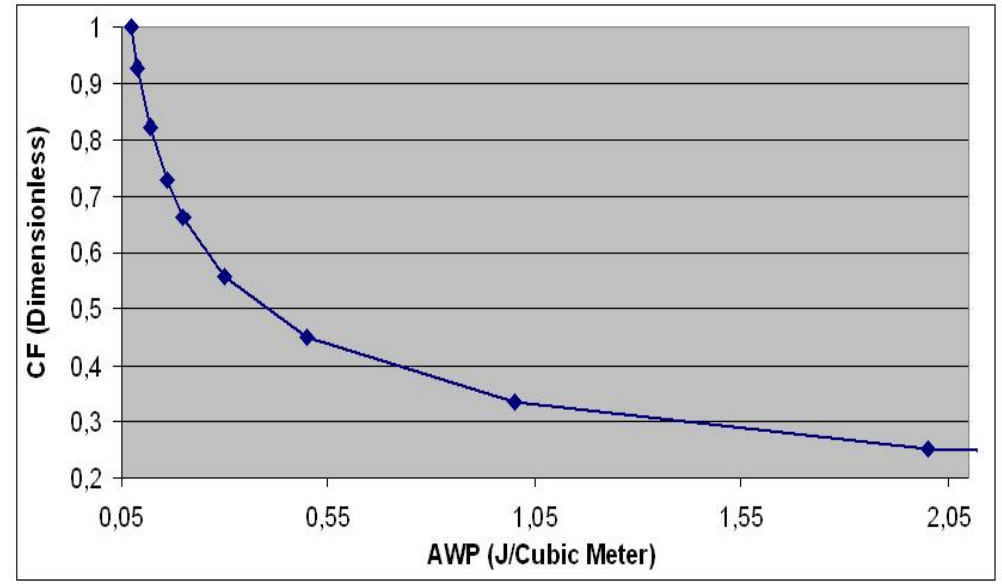

Figure 10: AWP versus CF

The CF curve was derived from (B.22) by normalising its value to 1.0 at an average gas price of $0.075 \mathrm{GBP} /$ cubic meter (the gas price in 2004). The consumption rate (CR) is computed as indicated by (B.23). 
Finally, in the production-consumption sector, production should be linked with the actual consumption. Based on information about the actual consumption rate, producers regulate their production capacity in order for their production rate to equal the actual consumption rate. Formally, production rate is computed as in (B.24).

The combined logic of all the feedback loops (B4 and B5) in the production-consumption sector is that producer willingness to invest in production is driven by industry's ROI and the actual consumption rate, which is driven by price dynamics.

\subsection{Demand projection and substitution sector}

The demand and substitution sector has only one balancing loop, B6 (figure 11). The loop works as follows: an increase in gas demand causes gas price to increase through RRDR. The increase in gas price leads to a rise in the share of other fuels in total primary energy demand (TPED). The increase in the share of other fuels in TPED closes the loop and ensures that the natural gas demand will be lower than it otherwise would have been.

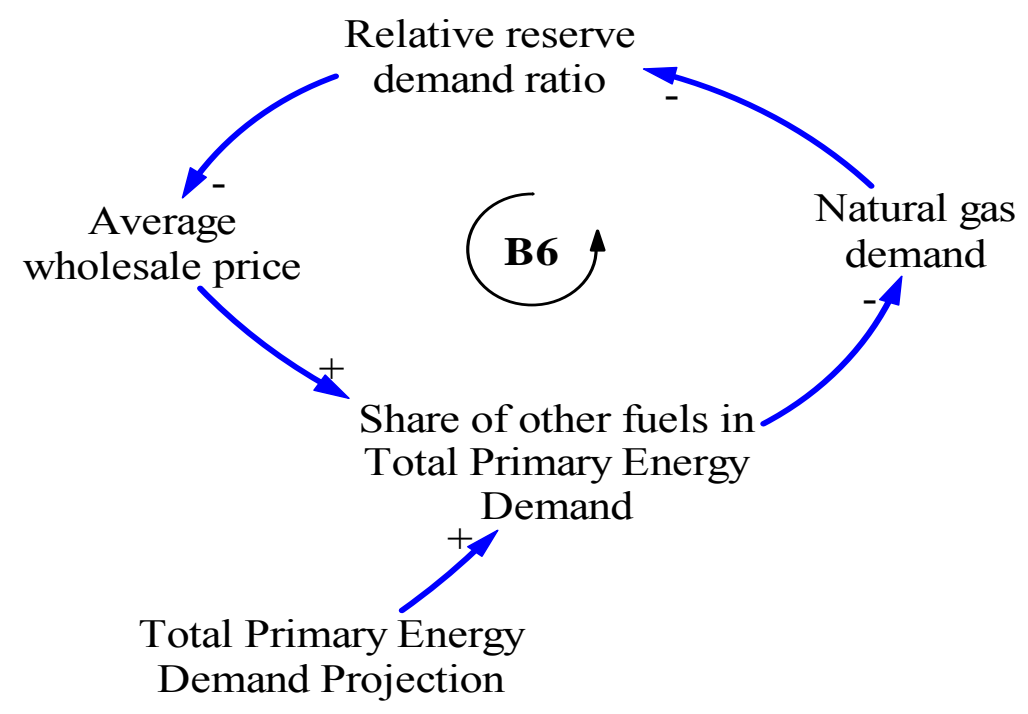

Figure 11: Causal loop diagram of demand projection and substitution sector

From the demand side we have introduced the substitution effect between natural gas and its main competitor fuels in TPED, i.e. coal, oil, nuclear, hydro. We assumed that coal, oil, nuclear and hydro shares in TPED are a function of gas price and time which represents other unaccounted factors determining the dynamics of energy demand. To check these assumptions the regressions were performed on 1976-2005 data for average gas price, coal, oil, nuclear and hydro energy demand (Earp, 2007; DTI 2006b). The regression results are reported in appendix B (eqn. B.25-B.28).

Regression results for coal, oil and nuclear were all significant (eqn. B.25-B.27), whereas the relationship between hydro share (HS) in TPED and gas price dynamics were not (B.28), hence we excluded the hydro relationship from further analysis of gas substitution factors. Except for the oil share 
equation (B.26) all price coefficients have a positive sign, which indicates that an increase in gas price would cause demand for the other fuels to rise.

The regression for oil share (eqn. B.26) yielded a negative price coefficient and is relatively inelastic. This suggests that an increase in gas price would reduce demand for oil. This is due to the comovement of oil and gas prices in UK. As mentioned earlier, the supply of associated gas in the UK has been growing and in 2004 reached about 55\% of total landed UKCS gas production (Wright, 2006). Secondly, due to the opening of the UK-Belgium Interconnector in October 1998 UK gas prices are partly influenced by European continental gas prices which are indexed to oil and oil-products (ILEX, 2004). Thirdly, Panagiotidis et al. (2004) analyzed UK oil and gas prices between 1996 and 2003 and found that they are cointegrated, i.e. move together over the longer-term (Panagiotidis et al., 2004).

Usually when oil price is high, producers tend to increase oil production by maintaining high pressure in the wells by keeping associated gas underground, thus reducing gas supply which logically leads to an increase in gas price. But high oil prices would, on net, cause its share in TPED to decrease and therefore it is incorrect to infer that high gas price would lead to a decrease in the oil share of TPED. Since the causality between gas price and oil demand cannot be robustly inferred from empirical data, we excluded the relationship between oil demand and gas price from further analysis of gas substitution factors.

The substitution factors shown in figure 12 were derived from eqn. B.25 and B.26 (appendix B) by normalising their value to 1.0 at an average gas price of $0.044 \mathrm{GBP} /$ cubic meter (gas price in 1987). The Oil and Hydro shares in TPED are assumed to be exogenously determined. The calculation of gas demand is shown in appendix B (eqn. B.29-B.35).

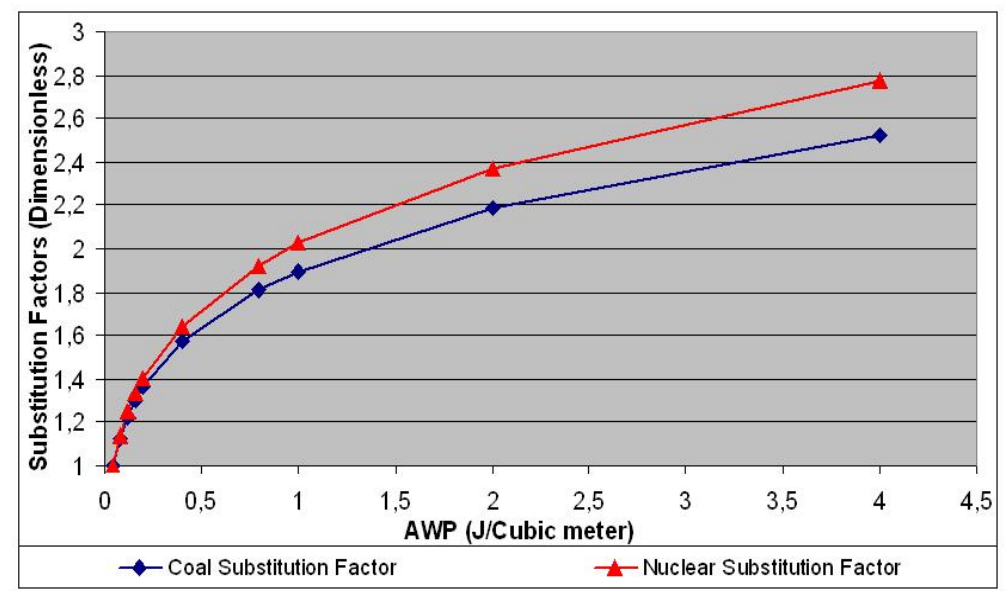

Figure 12: AWP versus substitution factors

\section{Dynamic behaviour and validation of the model}

The model results correspond relatively well to general trends for real-world data, particularly for consumption rate, cumulative gas production, share of fuels in TPED and others (see figure 13-16). 


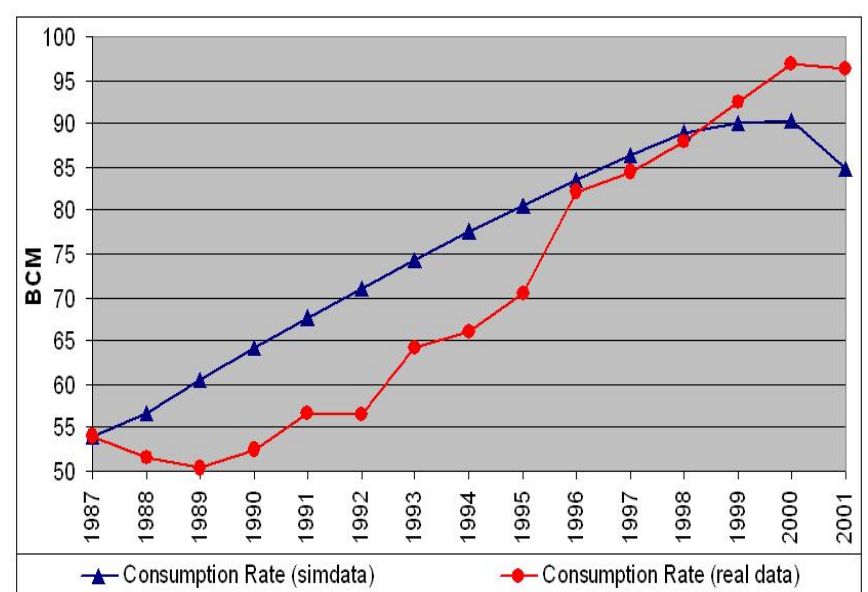

Figure 13: Consumption rate: simulated vs. real data

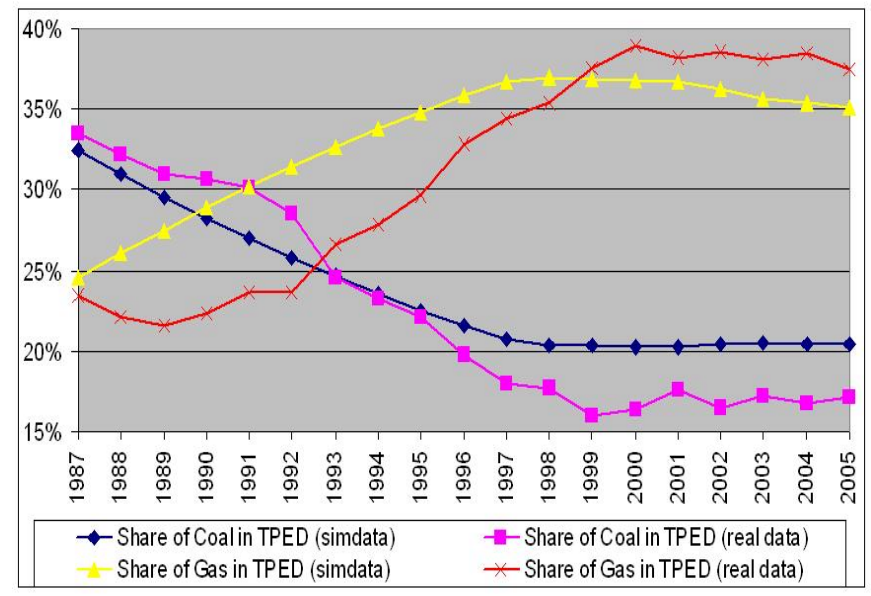

Figure 15: Shares of coal and gas in TPED: simulated vs. real data

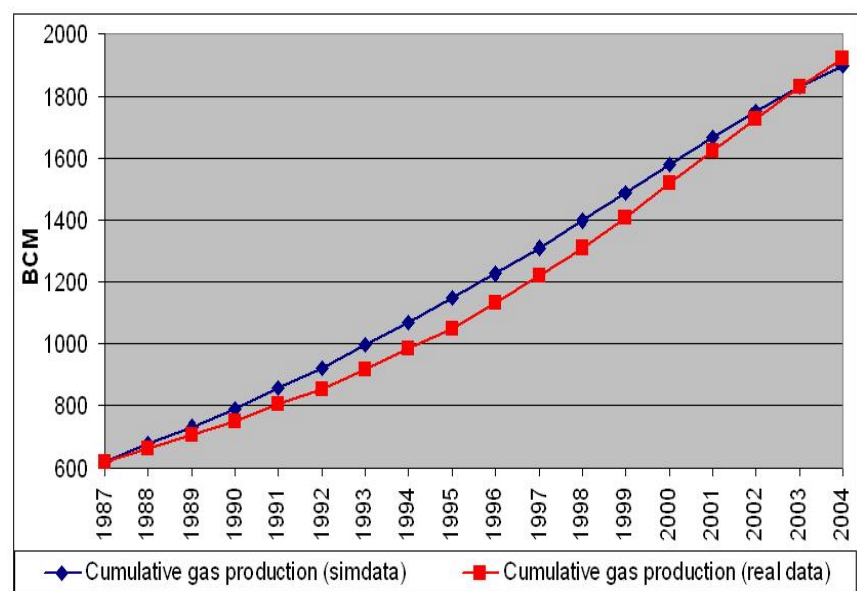

Figure 14: Cumulative gas production: simulated vs. real data

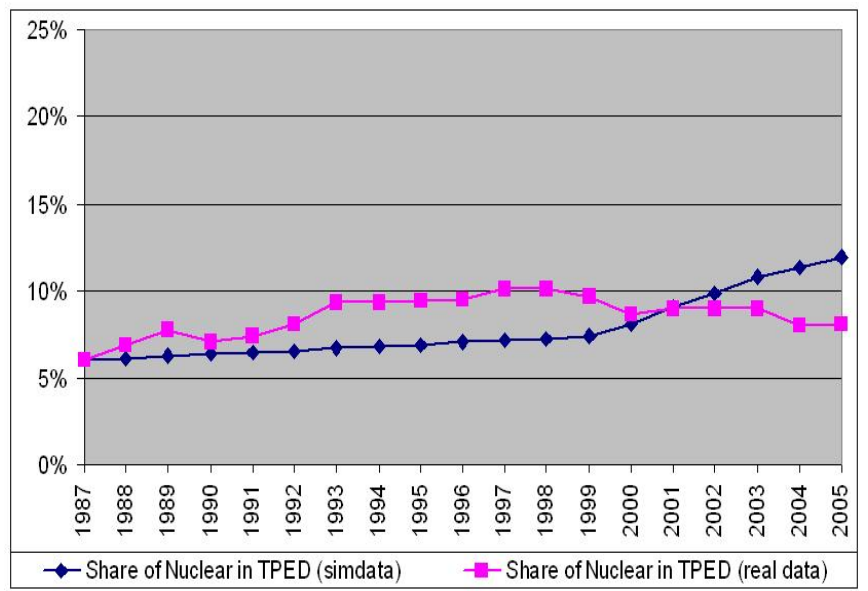

Figure 16: Shares of nuclear in TPED: simulated vs. real data

Some variables are generally consistent with historical data (e.g. cumulative gas production) while others diverge for part of the time series (e.g. consumption rate). One reason for the discrepancy in the trend (particularly in the period after 2000 for nuclear share and consumption) is that our model does not account for imported gas, leading gas prices to be somewhat higher in the model. Another reason might be that two or more variables are interdependent as result of the feedback loops in our model. Where simultaneity is present, the literature on regression warns that the use of OLS regression methods can give biased estimates of the regression coefficients (Jonhston, 1997). The non-linear relationship in our model which was derived from OLS regressions may therefore be different from the actual real-world relationship. Therefore we must be aware of the results of OLS regressions in a system with feedbackloop structure.

The feedback structure of our model may introduce biases in the relationships that we have derived from OLS regressions on historical data. If there are biases in the results produced by our model than an important objective is at least to measure and report those biases. The bias can be measured by analysing synthetic data (i.e., data from our model) and comparing them with historical data. The 
difference between the coefficients inferred statistically from the simulation of the synthetic data and that of real-world time series gives an approximate measure of the bias. Thus, simulation provides a method to check the validity of assumptions made when applying linear regression methods to System Dynamics models. This estimation procedure was applied to the table functions of our model (the factor and multiplier curves in our model) and the results are reported in Table 1.

Table 1: Comparison of regressions on real and synthetic data

\begin{tabular}{|c|c|c|}
\hline Table functions & OLS regressions on historical data & OLS regressions on synthetic data \\
\hline \multirow[t]{2}{*}{ COE\&A Multiplier } & $\operatorname{Ln}(C O E \& A)=-21.66 \operatorname{Ln}(F U R R)-4.5$ & $\operatorname{Ln}(C O E \& A)=-21.95 \operatorname{Ln}(F U R R)-4.33$ \\
\hline & $\mathrm{R}^{2}=.731 ; \mathrm{SER}=.44$ & $\mathrm{R}^{2}=.99 ; \mathrm{SER}=.06$ \\
\hline \multirow[t]{2}{*}{ ROI Factor } & $\operatorname{Ln}(P S I E \& A)=0.68 \operatorname{Ln}(R O I)-1.2$ & $\operatorname{Ln}(P S I E \& A)=0.686 \operatorname{Ln}(R O I)-1.19$ \\
\hline & $\mathrm{R}^{2}=.96 ; \mathrm{SER}=.04$ & $\mathrm{R}^{2}=.99 ; \mathrm{SER}=.001 \quad(0.001) \quad(0.00012)$ \\
\hline \multirow[t]{2}{*}{ RRDR Factor } & $\operatorname{Ln}(P S I E \& A)=-1.04 \operatorname{Ln}(R R D R)-0.95$ & $\operatorname{Ln}(P S I E \& A)=-0.99 \operatorname{Ln}(R R D R)-1.4$ \\
\hline & $\mathrm{R}^{2}=.97 ; \mathrm{SER}=.036$ & $\mathrm{R}^{2}=.92 ; \mathrm{SER}=.12$ \\
\hline \multirow[t]{2}{*}{ PC Factor } & $\operatorname{Ln}(P C)=0.28-1.56 \operatorname{Ln}(R R P R)$ & $\operatorname{Ln}(P C)=0.38-1.52 \operatorname{Ln}(R R P R)$ \\
\hline & $\begin{array}{l}\mathrm{R}^{2}=.92 ; \\
\mathrm{SER}=.11\end{array}$ & $\begin{array}{l}\mathrm{R}^{2}=.99 ; \quad(0.019) \\
\mathrm{SER}=.09\end{array}$ \\
\hline \multirow[t]{2}{*}{ PSIP Factor } & $\operatorname{Ln}(P S I P)=0.88 \operatorname{Ln}(R O I)-1.098$ & $\operatorname{Ln}(P S I P)=0.82 \operatorname{Ln}(R O I)-1.13$ \\
\hline & $\mathrm{R}^{2}=.82 \quad \begin{array}{ll}(0.24) \\
\mathrm{SER}=.1\end{array}$ & $\mathrm{R}^{2}=.99 ; \mathrm{SER}=.001$ \\
\hline \multirow[t]{2}{*}{ Price Factor } & $\operatorname{Ln}(P)=0.11-2.03 \operatorname{Ln}(R R D R)$ & $\operatorname{Ln}(P)=0.83-2.01 \operatorname{Ln}(R R D R)$ \\
\hline & $\begin{array}{l}\mathrm{R}^{2}=.9 ;(0.03) \\
\mathrm{SER}=.08\end{array}$ & $\begin{array}{l}\mathrm{R}^{2}=.99 ;(0.005) \\
\mathrm{SER}=.02\end{array}$ \\
\hline \multirow{2}{*}{$\begin{array}{l}\text { Consumption } \\
\text { Factor }\end{array}$} & $\operatorname{Ln}(C)=2.56-0.42 \operatorname{Ln}(P)+0.054(t)$ & $\operatorname{Ln}(C)=2.9-0.46 \operatorname{Ln}(P)+0.06(t)$ \\
\hline & $\mathrm{R}^{2}=.945^{(0.41)} \mathrm{SER}=.063$ & $\mathrm{R}^{2}=.96 \stackrel{(0.28) \quad(0.07) \quad(0.009)}{\mathrm{SER}=.18}$ \\
\hline \multirow{2}{*}{$\begin{array}{l}\text { Coal substitution } \\
\text { Factor }\end{array}$} & $\operatorname{Ln}(C S)=0.206 \operatorname{Ln}(P)-0.046(t)-0.001$ & $\operatorname{Ln}(C S)=0.206 \operatorname{Ln}(P)-0.046(t)-0.054$ \\
\hline & $\begin{array}{lr}(0.049) & (0.004) \quad(0.21) \\
\mathrm{R}^{2}=.917 & \mathrm{SER}=.089\end{array}$ & $\begin{array}{ll}(0.002) & (0.0003)(0.008) \\
\mathrm{R}^{2}=.99 & \mathrm{SER}=.002\end{array}$ \\
\hline \multirow[t]{2}{*}{$\begin{array}{l}\text { Nuclear } \\
\text { substitution Factor }\end{array}$} & $\operatorname{Ln}(N S)=0.227 \operatorname{Ln}(P)+0.017(t)-2.19$ & 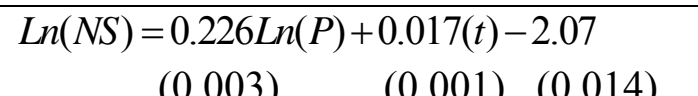 \\
\hline & $\mathrm{R}^{2}=.845 \quad \mathrm{SER}=.12$ & $\mathrm{R}^{2}=.99 \quad \mathrm{SER}=.004$ \\
\hline
\end{tabular}

Figure 17 and 18 show the behaviour of the UK model of indigenous gas production under the Base case assumptions (i.e., the model is simulated using actual UK gas industry data). The production rate peaked in 2000. The production rate is constrained by proved reserves, actual consumption, and investment potential. As proved reserves begin to fall, the production rate follows this trend.

The AWP remains low until the variable RDR falls below 20 years (figure 18). The expectation of a future reserves deficit based on demand projections causes the price to go up, signalling that additional discoveries are required. For example, during 2001-2008, industry responded to high prices by tapping additional discoveries (figure 17). DR stayed at a low level thereafter (figure 17) since a further decrease in RDR causes AWP to rise, which depresses consumption and production. In reality, consumption will continue to rise because gas imports will balance out increasing prices for indigenous UK gas. 


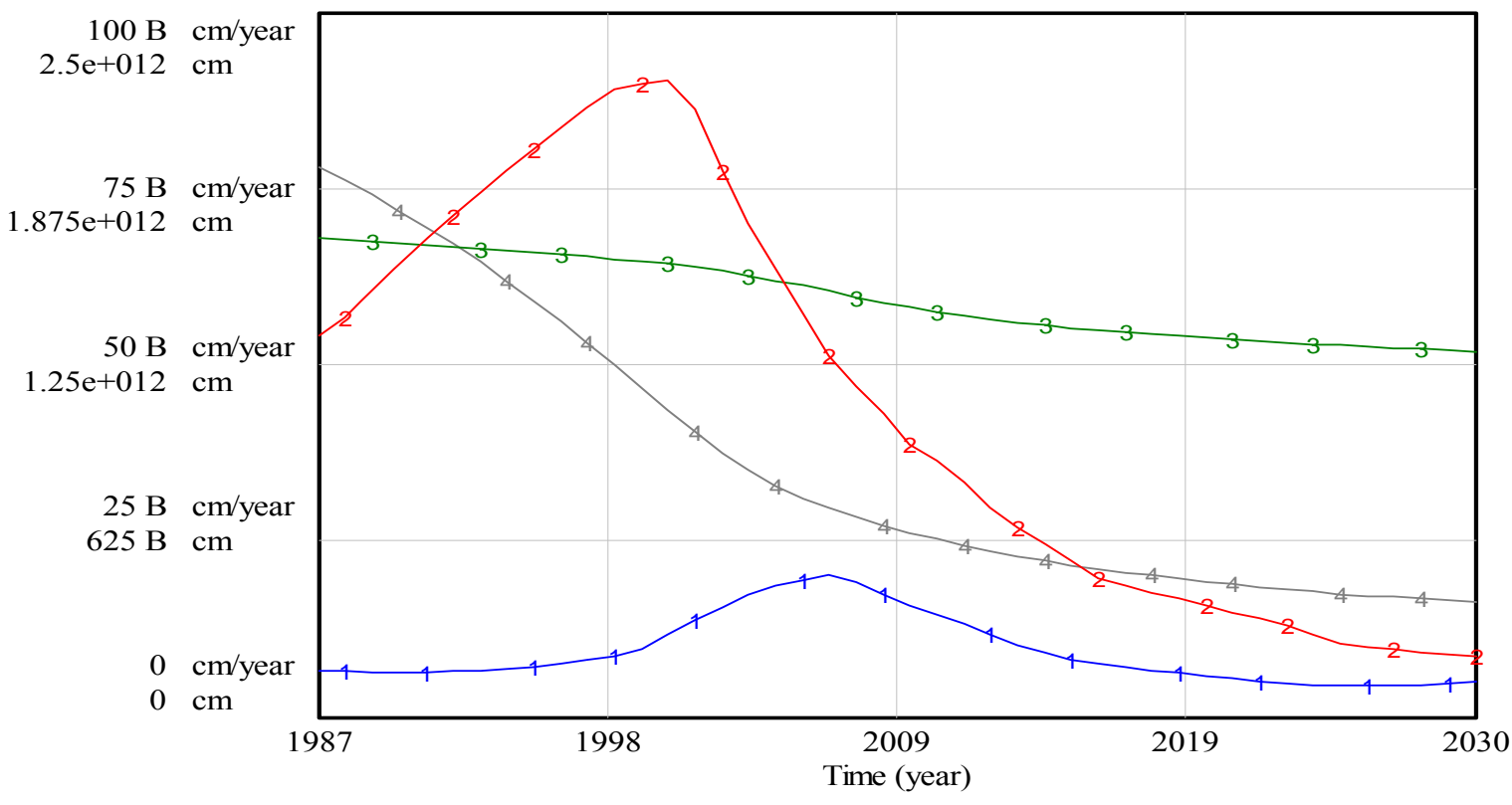

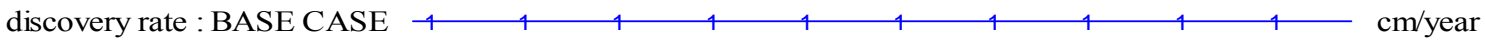

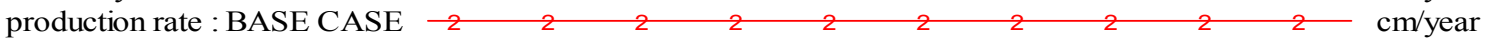
Undiscovered reserves : BASE CASE $3 \begin{array}{lllllll}3 & 3 & 3 & 3 & 3 & 3 & 3\end{array}$ $\begin{array}{llllllllllllll}\text { Proved reserves : BASE CASE } & 4 & 4 & 4 & 4 & 4 & 4 & 4 & 4 & 4 & 4\end{array}$

\section{Figure 17: Behaviour of DR, PRR, UR and PR in Base case*}

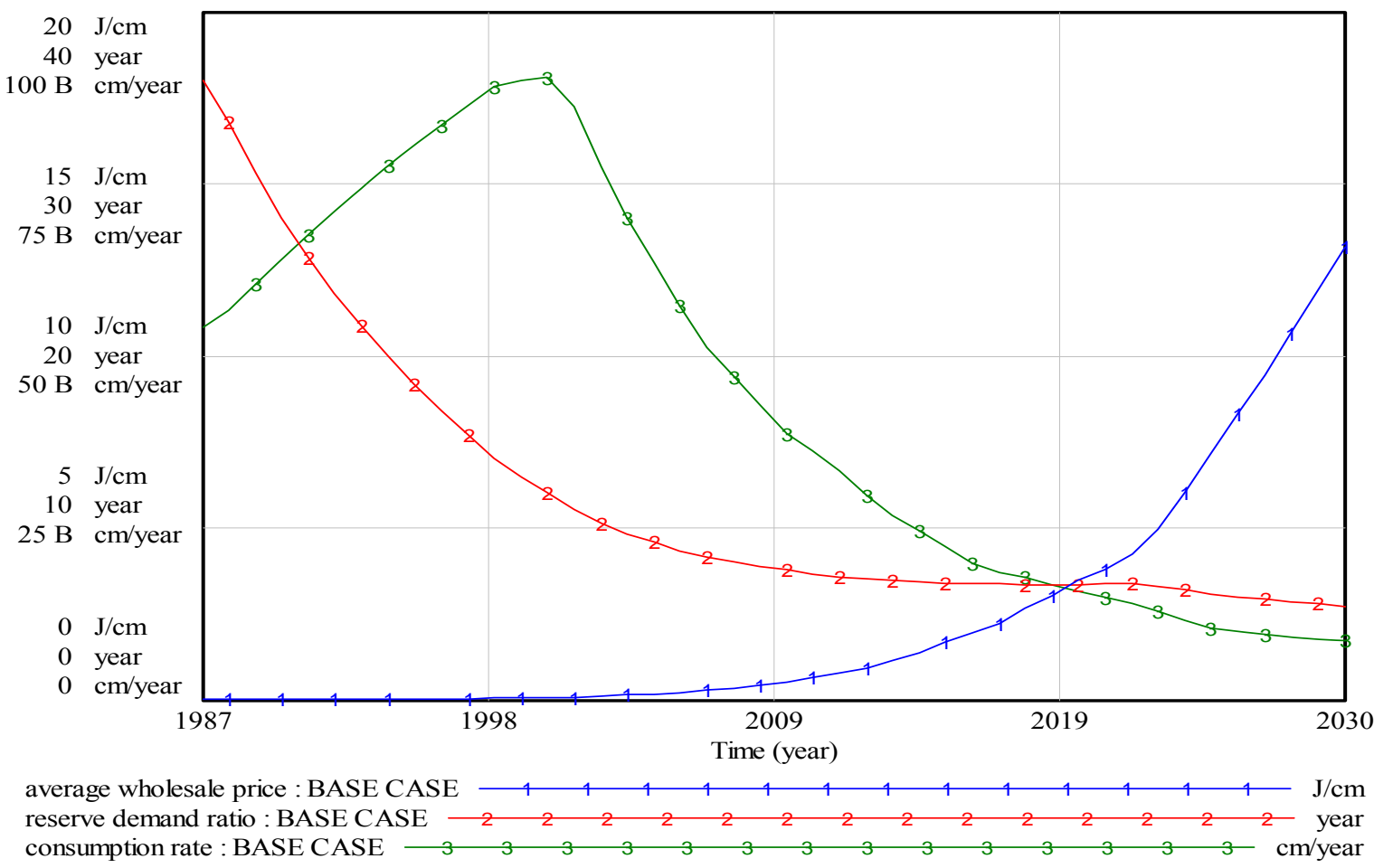

\section{Figure 18: Behaviour of AWP, RDR and CR in Base case ${ }^{\dagger}$}

\footnotetext{
* Discovery and production rate are measured in cubic meters/year (cm/year) so the $y$-axis for them begins with 0 till $100 \mathrm{~B}$ (Billion) $\mathrm{cm} /$ year; Undiscovered and Proved reserves are measured in cubic meter $(\mathrm{cm})$ so the y-axis for them begins with 0 up to $2.5 \mathrm{Bcm}$.

${ }^{\dagger}$ Price is measured as GBP/cubic meter $(\mathrm{J} / \mathrm{cm})$ so the $\mathrm{Y}$-axis runs from 0 through $40 \mathrm{~J} / \mathrm{cm}$; Reserve-demand ratio is measured in years so the $\mathrm{Y}$-axis is 0 up to 40 years; and consumption rate is measured in cubic meters/year (cm/year), so the scale of its $\mathrm{Y}$-axis is 0 to $100 \mathrm{BCM}$.
} 


\section{Analysis of alternative scenarios}

The success in matching historical data does not ensure the reliability of forecasts... As Sterman (2000) notes: “...the ability of the model to replicate historical data does not, by itself, indicate that the model is useful". In this section we develop a range of scenarios to examine model behaviour across various possible futures. These scenarios do not represent any particular government policies existing now or in the past. Rather, they are answers to 'what if' questions and represent a range of possible policies in a declining gas production industry. Since the model was calibrated using 1987 industry data (the earliest possible year where all data required for our model was available). The alternative scenarios will be introduced at the beginning of the model run.

The objective of the model is to examine various policies which could affect the development of the UK gas industry. For example, using the model we compare various taxation policies and technological development scenarios. We also check how the model behaves in extreme demand cases. The assumptions of growth rate of gas demand scenarios should be regarded as extreme values rather than real demand projection. So to analyse these issues we consider cases with the following assumptions:

1. Low taxation policy (both Royalty and Petroleum Revenue Tax (PRT) are 0\%)

2. High taxation policy (Royalty is $20 \%$, PRT is $70 \%$ )

3. High demand projection $-7 \%$ growth per year (compared to $3.5 \%$ p.a. in the Base case) ${ }^{\dagger}$

4. Low demand projection $-1 \%$ growth per year

5. Advanced exploration and recovery technologies - we assume that with advanced technologies the unit cost of exploration and production would decline at $5.33 \%$ per yeart.

\subsection{Taxation policy cases}

In general taxation policy (TP) cases have the strongest impact on discovery rate. As was discussed earlier discovery rate (DR) is affected by two factors - industry's ROI and future demand. Since taxation policy has a direct influence on industry's returns, higher taxation policy, ceteris paribus, decreases industry's returns and hence its investment in E\&A (loop B2). In the low taxation case (LTC), initial value of DR is $33 \%$ higher than in the Base case due to higher ROI which directly affects E\&A investment (see table 2). Due to anticipated demand growth, DR in both cases (LTC and High taxation cases (HTC) rises in the period 2000-2006. The turning points of DR are the same in all three cases (figure 19).

\footnotetext{
${ }^{*}$ Real taxation policy for UK indigenous oil and gas production as of May 2007 is as follows: Royalty is $12.5 \%$ for all fields which were developed before 1982, after that time Royalty is 0\%; PRT is 50\% for all fields which were developed before 1993 after that time PRT is $0 \%$ (BERR, 2007b)

$\dagger$ The growth rates for the demand cases were based on historical trends in UK natural gas consumption from 1965-2005, which varies considerably over the time horizon. In the initial period of introduction of gas usage in UK 1965-1974 average annual growth rate was 48\%; in the period 1975-1984 average growth rate was $3.31 \%$; in the period 1985-1995 average growth rate was 3\%; in the period 1996-2005 average growth rate was 1.7\% (authors' calculations based on DTI, 2006b).

$\$$ A $5.33 \%$ p.a. reduction in cost of exploration resulting from technological advancements was taken from (IEA, 2005).
} 


\section{discovery rate}

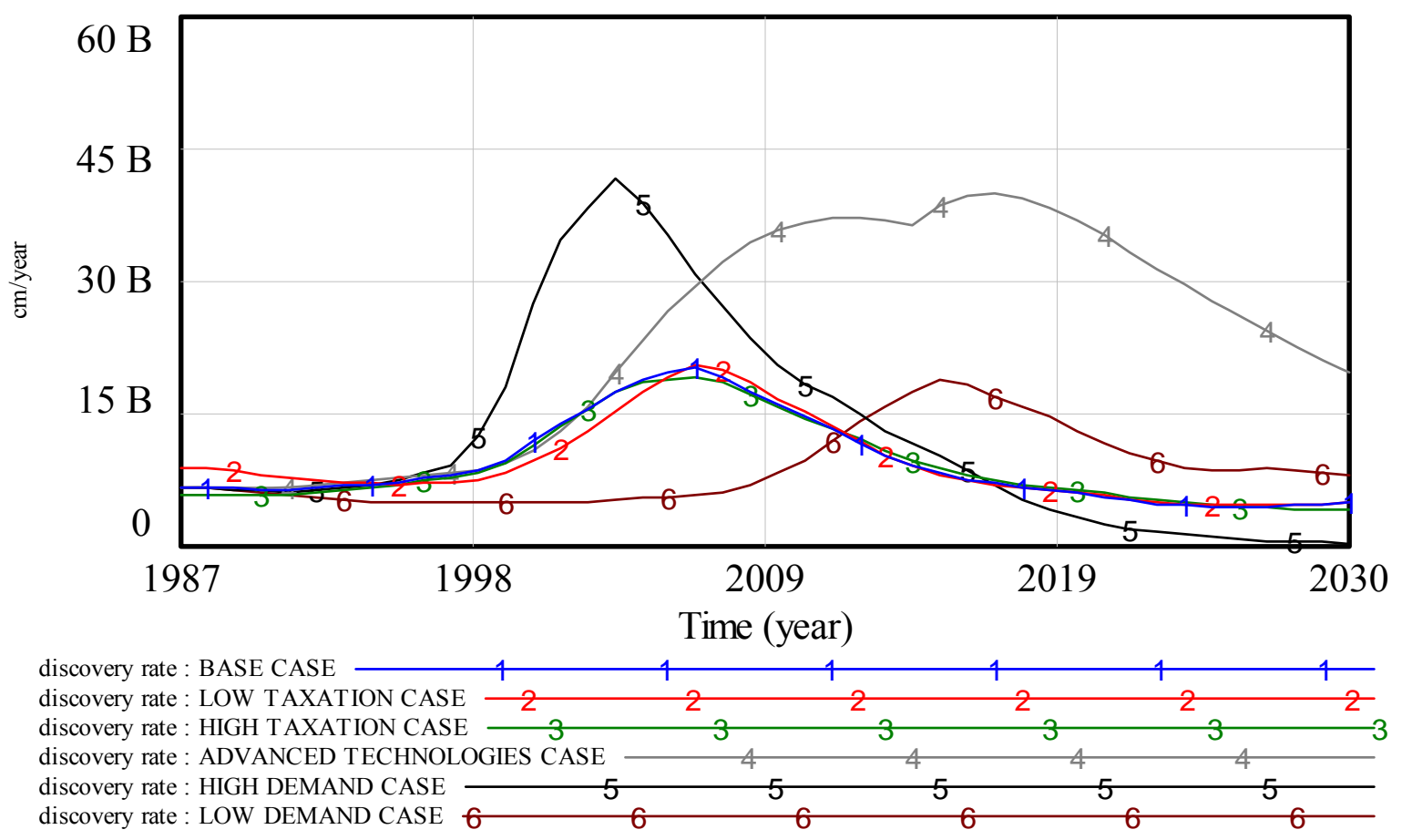

\section{Figure 19: Dynamics of DR in alternative cases}

In general, HTC discourages discovery of gas in the short-term and the initial value of DR is $13 \%$ less than that of Base case. The LTC might be expected to encourage more discoveries, but the cumulative gas discovery for this case is actually $0.2 \%$ lower than that of Base case. In the HTC, the cumulative gas discovery is about $1.8 \%$ less in value than that of Base case. These results suggest that TP cases are most efficient in the short-term and their relative effectiveness in the long run do not differ considerably from that of Base case. The analysis of production, consumption and price patterns in TP cases yields almost the same results (Table 2). 
Table 2: Main variables' turning points and discrepancies from Base Case (BC) results

\begin{tabular}{|c|c|c|c|c|c|c|c|c|c|c|}
\hline \multirow[b]{3}{*}{ Alternative } & \multicolumn{3}{|c|}{ Discovery rate } & \multicolumn{3}{|c|}{ Consumption rate } & \multirow{2}{*}{\begin{tabular}{|l}
$\begin{array}{l}\text { Undiscovered } \\
\text { reserves }\end{array}$ \\
Cumulative \\
value relative \\
to $\mathrm{BC}$
\end{tabular}} & \multirow{2}{*}{$\begin{array}{l}\begin{array}{l}\text { Proved } \\
\text { reserves }\end{array} \\
\text { Cumulative } \\
\text { value } \\
\text { relative to } \\
\mathrm{BC}\end{array}$} & \multicolumn{2}{|l|}{ AWP } \\
\hline & \multicolumn{2}{|c|}{ Turning point } & \multirow{2}{*}{$\begin{array}{l}\text { Cumulative } \\
\text { value } \\
\text { relative to } \\
\mathrm{BC}\end{array}$} & \multicolumn{2}{|c|}{ Turning point } & \multirow{2}{*}{$\begin{array}{l}\text { Cumulative } \\
\text { value } \\
\text { relative to } \\
\text { BC }\end{array}$} & & & \multirow[b]{2}{*}{$\begin{array}{l}\text { Time when } \\
\text { AWP } \\
\text { exceeds } 0.9 \\
\text { GBP/cm } \\
\text { (which is } \\
\text { roughly ten } \\
\text { times the } \\
\text { level of } \\
2005 \text { gas } \\
\text { price ) }\end{array}$} & \multirow[b]{2}{*}{$\begin{array}{l}\text { Price at } \\
\text { the end of } \\
\text { simulation } \\
\text { (relative to } \\
\text { BC) }\end{array}$} \\
\hline & Year & $\begin{array}{l}\text { Relative } \\
\text { to } \mathrm{BC}\end{array}$ & & Year & $\begin{array}{l}\text { Relative } \\
\text { to } \mathrm{BC}\end{array}$ & & $\begin{array}{l}\text { value relative } \\
\text { to } \mathrm{BC}\end{array}$ & $\begin{array}{l}\text { value } \\
\text { relative to } \\
\mathrm{BC}\end{array}$ & & \\
\hline Base case (BC) & 2006 & --- & --- & 2000 & --- & --- & --- & --- & 2012 & --- \\
\hline Low taxation case & 2006 & $+2 \%$ & $-0.27 \%$ & 2000 & $-0.1 \%$ & $-0.4 \%$ & $-0.1 \%$ & $+0.5 \%$ & 2013 & $-2.3 \%$ \\
\hline High taxation case & 2006 & $-4.5 \%$ & $-1.7 \%$ & 2000 & $+0.01 \%$ & $+0.3 \%$ & $+0.5 \%$ & $-1.1 \%$ & 2012 & $-3.1 \%$ \\
\hline $\begin{array}{l}\text { Advanced technology } \\
\text { case }\end{array}$ & 2017 & $+99 \%$ & $+149 \%$ & 2000 & $+0.2 \%$ & $+16.7 \%$ & $-12 \%$ & $+11 \%$ & 2018 & $-74.8 \%$ \\
\hline Low demand case & 2015 & $-7 \%$ & $+33 \%$ & 2007 & $-27.6 \%$ & $-0.9 \%$ & $+17.2 \%$ & $+7.8 \%$ & 2020 & $-41.5 \%$ \\
\hline High demand case & 2003 & $+107 \%$ & $-6.3 \%$ & 1998 & $+19.4 \%$ & $-13.7 \%$ & $-10.5 \%$ & $+16 \%$ & 2005 & $+1400 \%$ \\
\hline
\end{tabular}




\subsection{High and Low Demand cases}

The analysis of demand cases shows that the model is quite sensitive to initial demand conditions. In particular, the high demand case (HDC) shifts the peak of the discovery rate, so that it peaks three years earlier and was about $100 \%$ higher in value than in the Base case (table 2). The consequence of such a high rate of discoveries is a rapid increase in price due to the depletion effects on E\&A drilling costs. In general, the HDC forces both production and consumption to peak earlier with higher values than in the Base case but shortens the overall lifetime of both production and consumption.

Lower demand increases the RDR and thus discourages investment in E\&A. As a result, the DR peaks nine years later at a relatively lower level than in the Base case. Production and consumption follows the same pattern as DR. This case leads consumption to peak seven years later at a $28 \%$ lower value than the Base case. In the how demand case (LDC) the price stays low. This is due to the fact that low demand has constrained the DR throughout the modelling period and thus the gas price is lower than it otherwise would have been. Although gas prices in the demand cases vary considerably, they have limited effects on cumulative gas consumption (see table 2 ) due to a relatively low elasticity of consumption.

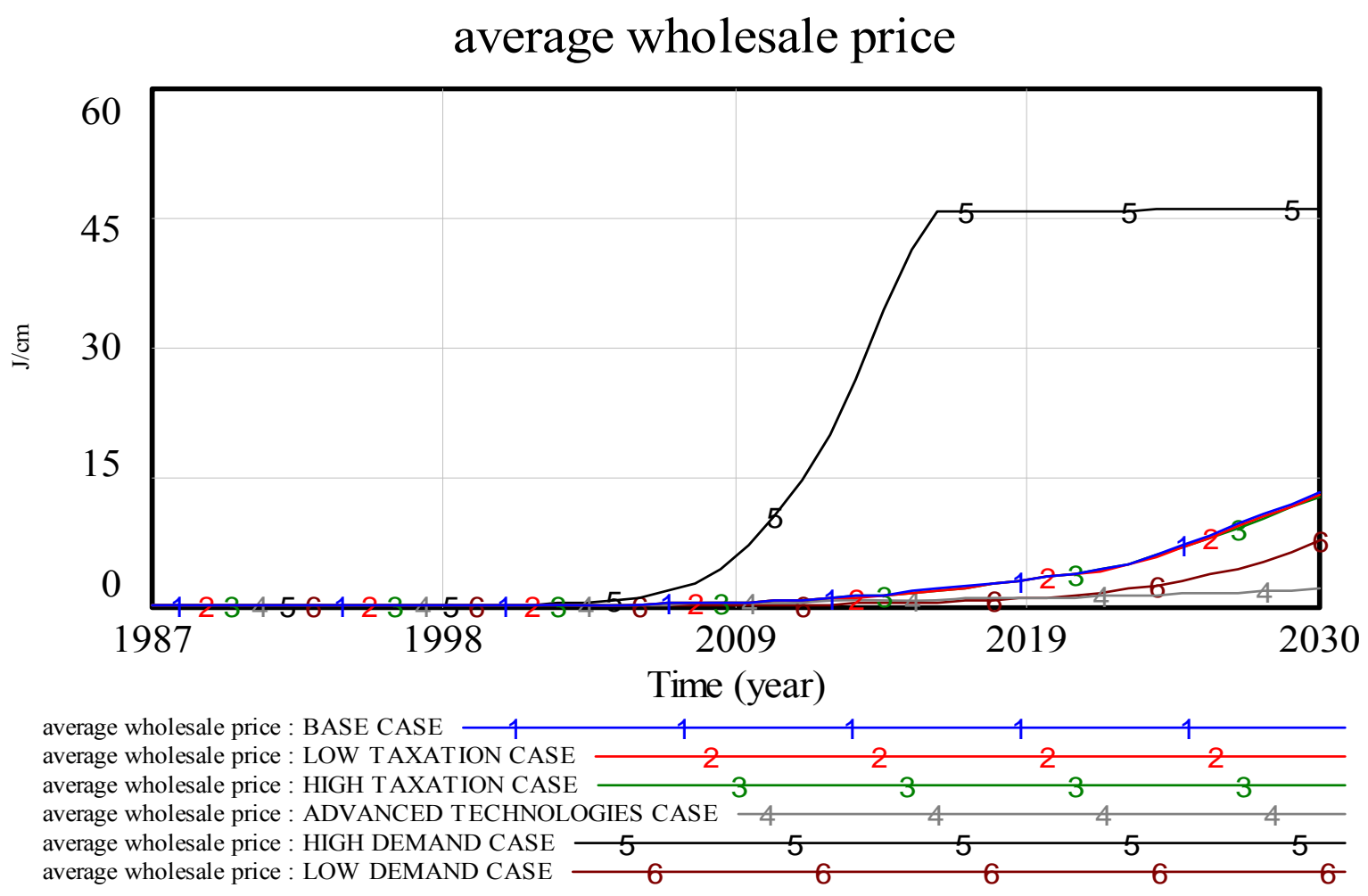

Figure 20: Dynamics of AWP in alternative cases

\subsection{Advanced technology case}

The impact of better exploration and production technologies on consumption rate is limited in the short-term but has a considerable effect in the long run. The cumulative gas consumption in this case is about $150 \%$ higher in value than in the Base case (figure 21). In the long term, lower costs of exploration 
and production resulting from technological improvements increases the discovery rate, production and consumption rates compared with the other cases (see, e.g., figures 19 and 21).

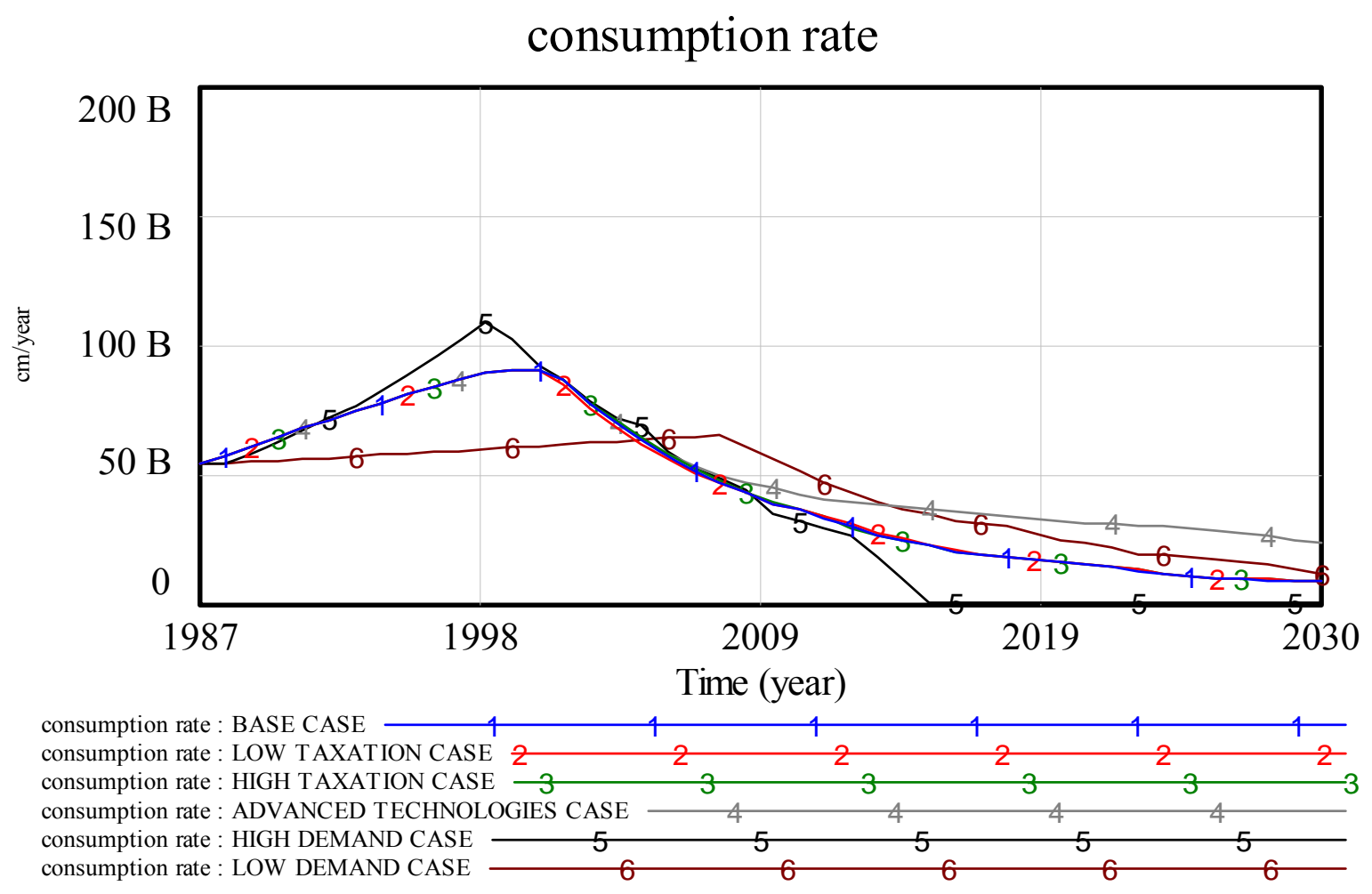

\section{Figure 21: Dynamics of $C R$ in alternative cases}

Due to the long-term effects of technological improvements, the consumption peaked at the same time as in the Base case. The direct impact of improvements in exploration and production technology is lower cost and consequently lower gas prices. The overall impact of improvements in exploration and production technology is to extend the lifetime of gas reserves and postpone the depletion effects on costs considerably allowing gas usage to continue for a longer time.

\subsection{Rising gas import-dependence in UK}

Analysis of alternative policies indicates that the most effective policies for prolonging indigenous gas production and consumption are those dealing with demand side, but the optimal policy should be one that combines both supply and demand side measures. Continued demand growth, depletion of gas resources, and long delays in the implementation of energy policy raise the possibility of a significant gap between gas demand and indigenous production. Under these conditions, the UK might rely on massive gas imports to balance supply and demand during the coming decades.

Figure 22 illustrates the results of the combined supply-demand policy (Supply-Demand case), which assumes: reduced demand (e.g. by successful implementation of energy efficiency policies), which would stabilise gas demand growth at $1 \%$ p.a.; and reduced taxation to encourage R\&D in exploration and production technology. The result of the combined policy is that, in the long-term, gas imports will be minimal due to extension of the lifetime of indigenous gas production which is associated with reliability 
and secure supplies for domestic customers. Management of import-dependence thus should not be reduced to focus solely on the design of responses to the unreliability of exporting countries but rather should emphasise the development of a combination of external and internal policies.

The size of the resource base in European countries such as the UK, Norway or Netherlands can only play a limited role in postponing the time when the EU would be heavily dependent on external gas resources. The only way to increase the reserve base is through technological advances, which in the past several decades has actually broadened the reserve base through improvements in recovery technologies (Butler, 2007).

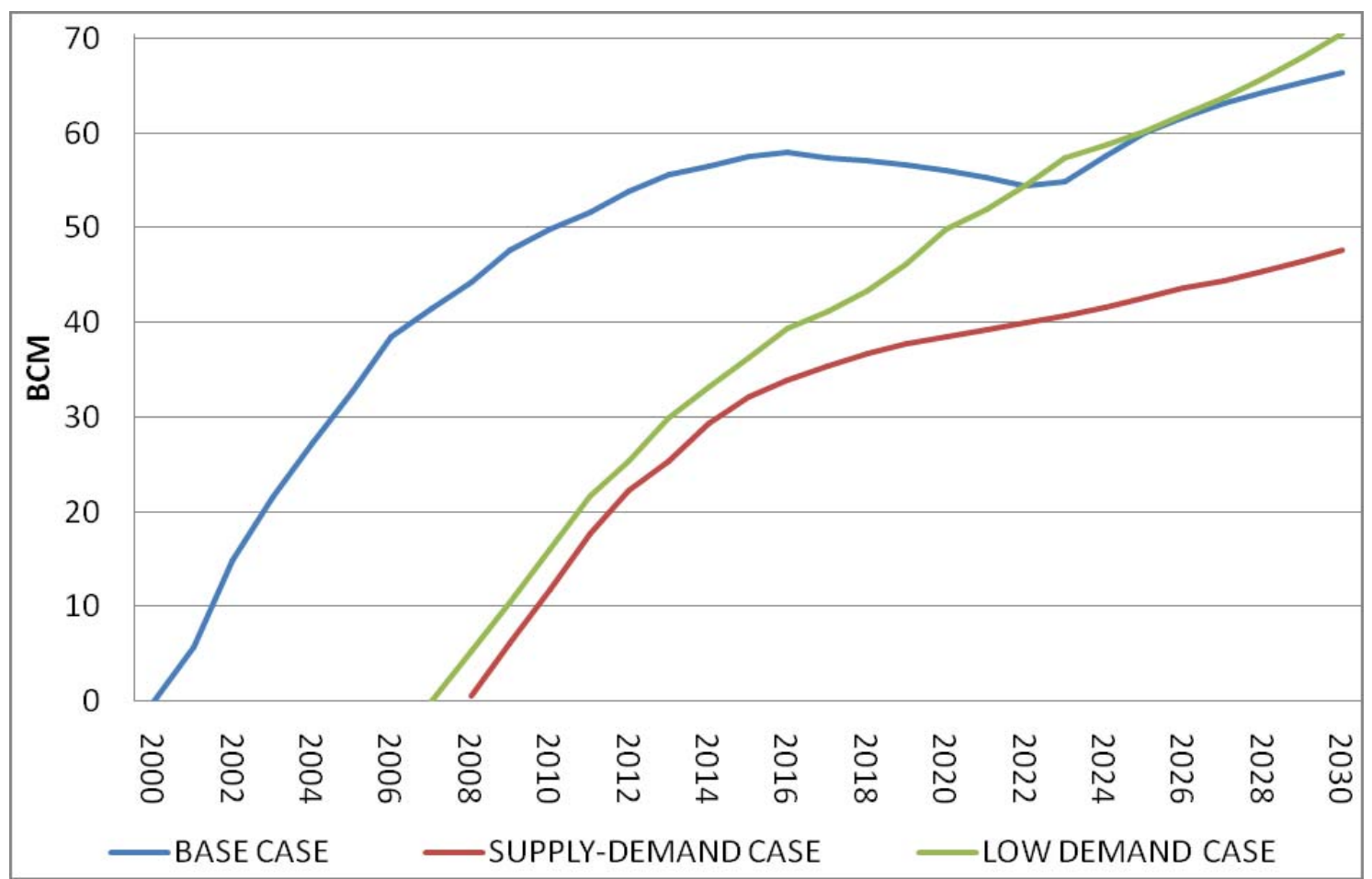

Figure 21: Dynamics of natural gas imports in alternative cases

\section{Conclusion}

As the UK becomes more dependent on natural gas imports, a new energy policy will be required. Efforts to design such a policy require long-range planning because of the lead times required for policies to have their full effect. For example, the growing gas import-dependence in the UK is a direct result of the policies adopted by successive governments during the past two decades e.g. those aimed at promoting the fastest possible exploitation of indigenous gas reserves and large-scale exports (Stern, 2004).

The model presented here could be useful for prediction purposes since it has shown minimal discrepancies with historical data of the main variables. The functional forms of the various assumptions made in this model are able to represent historical data and dynamic behaviours quite well, but there is no assurance that the same functional forms will be correct in the future. In any case, this type of model does offer a useful experimental tool for determining how various assumptions about physical, technological and economic factors affect patterns of growth or decline. 
By running different scenarios, several fundamental dynamic behaviours can be seen explicitly. For instance, the concept of exponential growth is very important for designing long-term energy policy since our analysis shows that supply policies (TP cases) alone cannot substantially postpone the discovery, production or consumption peak. We also found that main parameters, namely, exploration, production and consumption are quite sensitive to initial demand conditions. Postponing the onset of rising gas price can be achieved more effectively through efforts to reduce demand than through efforts directed at the supply-side. Improvements in exploration and production technology can delay the peak time of exploration, production and consumption. The overall effects of technological improvements are an increase in reserve life-time, lower gas price and consequently prolonged gas usage.

Nonlinear systems sometimes exhibit responses to policy changes that seem to support policy goals in the short term, but over the longer term, the system returns to its pre-policy-change state or produces an even worse situation. This reversion occurs when the system's feedback structure works to defeat the policy change designed to improve it (Sterman, 2000). A short-term policy of supply-side management, e.g. through various taxation policies, might exhibit policy resistance. For example, it is logical that the Low taxation policy should encourage more exploration and production of gas and therefore stimulate a higher consumption rate; but there were no substantial effects over the long-run, i.e. in the Low taxation case cumulative gas consumption is even less than that of the Base case. One explanation for the policy resistance could be the declining marginal rate of discovery which leads to higher cost, higher prices, and lower consumption over the long-term. 


\section{BIBLIOGRAPHY}

1. Adelman M. A. 1962, The Supply and Price of Natural Gas, supplement to Journal of Industrial Economics, Oxford: Basil Blackwell.

2. BERR (UK Department for Business Enterprise and Regulatory Reform, former DTI), 2007a, Digest of United Kingdom energy statistics 2007, Available at:

http://www.dti.gov.uk/energy/statistics/publications/dukes/page39771.html, accessed in May 2007

3. BERR (UK Department for Business, Enterprise and Regulatory Reform), 2007b, The UK Continental Shelf Tax Regime, Available at:

http://www.og.dti.gov.uk/upstream/taxation/index.htm, accessed in May 2007, accessed in May 2007

1. Bodger, P. S. and D. G. May, 1992, A system dynamics energy model of New Zealand, Technological Forecasting and Social Change 41(1): 97-106.

2. BP, 2007, Statistical Review of World Energy, Available at: http://www.bp.com/multipleimagesection.do?categoryId=6840\&contentId=7021557, accessed in May 2007

3. Bunn, D. W. and E. R. Larsen, 1992, Sensitivity reserve margin to factors influencing investment behaviour in the electricity market of England and Wales, Energy Policy 20(5): 420-429.

4. Bunn D. W., E. Larsen and K. Vlahos, 1993, Complementary modelling approaches for analysing several effects of privatisation on electricity investment, Journal of the Operational Research Society, 44(10): 957-971.

5. Bunn, D. W. and E. R. Larsen, 1994, Assessment of uncertainty and regulation of electricity investment using an industry simulation model, Utilities Policy, 4(3): 229-236.

6. Bunn D. W., Dyner I. and Larsen E., Modelling latent market power across gas and electricity markets, System Dynamics Review, 13(4): 271-288

7. Butler, N. J., 2007, Former Group Vice-President, Strategy and Policy Development, BP, United Kingdom. Interview with Mr. N.J. Butler at the University of Cambridge on 14/05/07

8. Chowdhurg, S. and K. C. Sahu, 1992, A system dynamics model for Indian oil and gas exploration/exploitation industry, Technological Forecasting and Social Change 42(1): 63-84.

9. Davidsen, P., J. Sterman and G. Richardson., 1990, A petroleum life cycle model for the United States with endogenous technology, exploration, recovery and demand, System Dynamics Review 6(1): 66-73.

10. DTI (UK Department of Trade and Industry), 2006a, The Effectiveness of Current Gas Security of Supply Arrangements: a Consultation, 16/10/2006, Available at:

http://www.dti.gov.uk/consultations/page34643.html, accessed in May 2007

11. DTI (UK Department of Trade and Industry), 2006b, The UK Energy Sector Indicators 2006, Available at: http://www.dti.gov.uk/energy/statistics/publications/indicators/page29741.html 
12. DTI (UK Department of Trade and Industry), 2007, The UK Oil and Gas Energy Reports 19982001 editions ("The Brown Book"), Available at: http://www.dbd-data.co.uk/brownbook/, accessed in May 2007

13. Dyner, I., R. Smith and G. Pena, 1993, System dynamics modelling for energy efficiency analysis, Proceedings of the 1993 Int. System Dynamics Conference (Cancun, Mexico), pp. 83-92.

14. Earp M. 2007, DTI Energy Market Unit, Comments and data on UK natural gas price (Email correspondence)

15. Ford, A., 1983, Using simulation for policy evaluation in the electric utility industry. Simulation 40(3): 85-92.

16. Ford, A., 1985, Short lead time technologies as a defence against demand uncertainty. In Strategic management and planning for electric utilities, eds. J. Plummer, E. Oatman and P. Gupta. Englewood Cliffs, NJ: Prentice-Hall.

17. Ford, A. and M. Bull.,1989, Using system dynamics for conservation policy analysis in the Pacific Northwest, System Dynamics Review 5(1): 1-16.

18. Ford, A., 1999, Cycles in competitive electricity markets: a simulation study of the Western United States, Energy Policy 27: 637-658

19. Ford, A., 2000, Simulating Patterns of Power Plant Construction with the California Energy Commission Model, Summary Report to the California Energy Commission, available at: www.wsu.edu/ forda/CECNov2000.pdf, accessed in May 2007.

20. Geraghty, D. M. and J. Lyneis, 1995, Feedback loops: the effect of external agents on utility performance, in Strategic Management and planning for electric utilities, eds. J. Plummer, E. Oatman, P. Gupta. Englewood Cliffs, NJ: Prentice-Hall.

21. Hubbert, M.K. 1956, Nuclear Energy and the Fossil Fuels, published in Drilling and Production Practice, American Petroleum Institute, Available at: http://www.energybulletin.net/13630.html, accessed in May 2007

22. ILEX Energy Consulting 2004, Gas Prices in the UK, Available at: www.oilandgas.org.uk/issues/gas/ilexreport.pdf, accessed in May 2007

23. International Energy Agency 2005, Resources to Reserves: Oil and Gas Technologies for the Energy Markets of the Future

24. Johnston, J. 1997, Econometric methods, $4^{\text {th }}$ ed., New York: McGraw-Hill

25. Kemp A., and Kasim, S., 2003, An Econometric Model of Oil and Gas Exploration Development and Production in the UK Continental Shelf: A Systems Approach, The Energy Journal, 24(2): 113-143

26. Khazzoom, J.D. 1971, “FPC Gas Model”, Bell Journal of Economics and Management, Vol. 2, no.1 (Spring 1971): p.71. 
27. Moxness, E. 1990, Interfuel substitution in OECD European electricity production, System Dynamics Review 6(1): 44-65.

28. Naill, R. F. 1973, The Discovery Life Cycle of a Finite Resource: A case study of U.S. natural gas, in Meadows, D. L. (Ed.) Toward Global Equilibrium: Collected Papers. Cambridge, MA: MIT Press.

29. Naill R. F. 1977, Managing the Energy Transition: A System Dynamics Search for Alternatives to Oil and Gas, Cambridge, MA: Ballinger Publishing Company.

30. Naill, R. F. 1992, A system dynamics model for national energy policy planning. System Dynamics Review 8(1): 1-19.

31. Naill, R., S. Belanger, A. Klinger and E. Peterson., 1992, An analysis of the cost effectiveness of U.S. energy policies to mitigate global warming, System Dynamics Review 8(2): 111-128.

32. Panagiotidis, T. and Rutledge, E. 2004, Oil and Gas Markets in the UK: Evidence from a Cointegrating Approach, Loughborough University, Department of Economics, Available at: http://www.lboro.ac.uk/departments/ec/Research/Discussion\%20Papers\%202004/Research\%20Pa pers\%202004/ee_wp.pdf, accessed in May 2007

33. Posner M.V., Eden R.J, Bending R., Crouch E., Stanislawski J., 1981, Energy Economics: Growth, Resources and Policies, Cambridge, UK: Cambridge University Press.

34. Rego, J. 1989, Schedule delays and new financing for the Argentine electricity sector growth, in Computer-based management of complex system, eds. P. Milling and E. Zahn, pp. 434-441. Berlin: Springer-Verlag.

35. Roche M., 1989, System dynamics applications in the sector of electricity, in Computer-based management of complex system, eds. P. Milling and E. Zahn, pp. 458-462. Berlin: SpringerVerlag.

36. Sterman, J., 1983, Economic vulnerability and the energy transition, Energy Systems and Policy, 7(4), 259-301.

37. Sterman J. D. and Richardson G. P., 1983, An Experiment to Evaluate Methods for Estimating Fossil Fuel Resources. Presented at the Third International Symposium on Forecasting, Philadelphia, PA, June 5-8, Available at: dspace.mit.edu/bitstream/1721.1/2046/1/SWP-143512141939.pdf, accessed in May 2007

38. Sterman J. D., 2000, Business Dynamics: System Thinking and Modelling for a Complex World, Englewood, NJ: McGraw-Hill.

39. Stern, J. 2004, UK gas security: time to get serious, Energy Policy, 32, 1967-1979

40. Wright, P. 2006, Gas Prices in the UK: Markets and Insecurity of Supply, Oxford Institute for Energy Studies, Oxford, UK: Oxford University Press.

41. USNPC (The US National Petroleum Council), 2003, Balancing Natural Gas Policy: Fuelling the Demand of Growing Economy, Available at: http://www.npc.org/, accessed in May 2007 
APPENDIX A

Table A.1: Main causal loops of the dynamic model of UK natural gas industry

\begin{tabular}{|c|c|c|c|c|c|}
\hline \multicolumn{3}{|c|}{ Exploration sector } & \multicolumn{2}{|c|}{$\begin{array}{l}\text { Production and } \\
\text { consumption sector }\end{array}$} & \multirow{2}{*}{$\begin{array}{l}\text { Demand and } \\
\text { substitution } \\
\text { sector } \\
\text { Loop B6 }\end{array}$} \\
\hline Loop B1 & Loop B2 & Loop B3 & Loop B4 & Loop B5 & \\
\hline $\begin{array}{l}\text { Undiscovered } \\
\text { reserves; } \\
\text { Fraction of } \\
\text { undiscovered } \\
\text { reserves } \\
\text { remaining; } \\
\text { Cost of } \\
\text { E\&A; } \\
\text { Indicated } \\
\text { discovery } \\
\text { rate; } \\
\text { Discovery } \\
\text { rate; } \\
\text { Undiscovered } \\
\text { reserves. }\end{array}$ & $\begin{array}{l}\text { Undiscovered } \\
\text { reserves; } \\
\text { Fraction of } \\
\text { undiscovered } \\
\text { reserves } \\
\text { remaining; } \\
\text { Cost E\&A; } \\
\text { Industry’s ROI; } \\
\text { Investment in } \\
\text { E\&A; } \\
\text { Indicated } \\
\text { discovery rate; } \\
\text { Discovery rate; } \\
\text { Undiscovered } \\
\text { reserves. }\end{array}$ & $\begin{array}{l}\text { Proved } \\
\text { reserves; } \\
\text { Relative } \\
\text { reserves } \\
\text { demand ratio; } \\
\text { Investment in } \\
\text { E\&A; } \\
\text { Indicated } \\
\text { discovery rate; } \\
\text { Discovery } \\
\text { rate; } \\
\text { Proved } \\
\text { reserves. }\end{array}$ & $\begin{array}{l}\text { Production } \\
\text { rate; } \\
\text { Relative } \\
\text { reserves } \\
\text { production } \\
\text { ratio; } \\
\text { Production } \\
\text { cost; } \\
\text { Industry's } \\
\text { ROI; } \\
\text { Desired } \\
\text { investment } \\
\text { in } \\
\text { production; } \\
\text { Desired } \\
\text { production } \\
\text { rate; } \\
\text { Production } \\
\text { rate. }\end{array}$ & $\begin{array}{l}\text { Production } \\
\text { rate; } \\
\text { Proved } \\
\text { reserves } \\
\text { Relative } \\
\text { reserve } \\
\text { demand ratio } \\
\text { Average } \\
\text { wholesale } \\
\text { price; } \\
\text { Consumption } \\
\text { rate: } \\
\text { Production } \\
\text { rate }\end{array}$ & $\begin{array}{l}\text { Relative reserve } \\
\text { demand ratio; } \\
\text { Average } \\
\text { wholesale price; } \\
\text { Share of other } \\
\text { fuels in TPED; } \\
\text { Natural gas } \\
\text { demand; } \\
\text { Relative reserve } \\
\text { demand ratio. }\end{array}$ \\
\hline
\end{tabular}




\section{APPENDIX B: Model Equations}

\section{Exploration Sector}

In order to explore the relationship between the cost of exploration drilling (COE\&A) and depletion of undiscovered reserves (FURR), a regression was performed on 1987-1998 data for UK gas industry. The regression yielded ${ }^{7}$ :

$\operatorname{Ln}(C O E \& A)=-21.66 \operatorname{Ln}(F U R R)-4.5$

$$
\mathrm{R}^{2}=.731 \quad \mathrm{SER}=.44
$$

(B.2) and (B.3) show how COE\&A is calculated.

$$
F U R R=\frac{U R}{I U R}
$$

$C O E \& A=C O E \& A M \times I C O E \& A$

FURR - Fraction of Undiscovered Reserves Remaining (Dimensionless)

UR - Undiscovered Reserves (Cubic meters)

IUR - Initial value of Undiscovered Reserves (Cubic meters)

COE\&A - Cost of exploration and appraisal (GBP/cubic meter)

COE\&AM - Cost of exploration and appraisal multiplier (Dimensionless)

ICOE\&A - Initial cost of exploration and appraisal (GBP/cubic meter)

The rate of gas discoverites is defined as follows:

$$
\begin{aligned}
& I D R=\frac{I E \& A}{C O E \& A} \\
& D R=D E L A Y(I D R, 4.5)
\end{aligned}
$$

IDR - Indicated discovery rate (Cubic meters/year)

IE\&A - Investment in exploration and appraisal (GBP/year)

COE\&A - Cost of exploration and appraisal (GBP/Cubic meter)

DR - Discovery rate (Cubic meters/year)

DELAY - Delay function

$4.5-4.5$ years of delay in the results of IE\&A drilling

The derivation of investment in gas exploration and appraisal drilling is based on regressions ${ }^{8}$ (equations B.6 and B.7) performed on 1987-1992 data for industry's ROI, RRDR and percentage of sales invested in E\&A (PSIE\&A) (BP, 2007; DTI, 2007).

\footnotetext{
${ }^{7}$ Throughout, the value in parentheses is the standard error. For eqn. B.1, T and F statistics for this regression are significant at the 1 per cent level.
} 


$$
\operatorname{Ln}(P S I E \& A)=-1.04 \operatorname{Ln}(R R D R)-0.95
$$

$$
\text { (0.14) (0.019) }
$$

$$
\begin{aligned}
& \mathrm{R}^{2}=.97 \quad \mathrm{SER}=.036 \\
& \operatorname{Ln}(P S I E \& A)=0.68 \operatorname{Ln}(R O I)-1.2
\end{aligned}
$$

$$
\begin{aligned}
& \mathrm{R}^{2}=.956 \quad \mathrm{SER}=.04 \\
& R R D R=\frac{R D R}{N R D R}=\frac{P R / N G D}{N R D R} \\
& R O I=\frac{A W P}{T U C}
\end{aligned}
$$

$P S I E \& A=R O I F \times R R D R F \times I P S I E \& A$

IE \& $A=P S I E \& A \times S R$

RDR - Reserve-demand ratio (Years)

PR- Proved reserves (Cubic meters)

NGD - Natural gas demand (Cubic meters/year)

RRDR - Relative reserve-demand ratio (Dimensionless)

NRDR -Normal reserve-demand ratio (10 years)

ROI - Industry's return on investment (\% per year)

AWP - Average wholesale price (GBP/cubic meter)

TUC - Total unit cost (GBP/cubic meter)

PSIE\&A - Percentage of sales invested in E\&A (\% per year)

IPSIE\&A - Initial percentage of sales invested in E\&A (37\% in 1987) (DTI, 2007)

ROIF - ROI Factor (Dimensionless)

RRDRF - RRDR Factor (Dimensionless)

IE\&A - Investment in exploration and appraisal (GBP/year)

$\mathrm{SR}$ - Sales revenue (GBP/year)

\section{Production sector}

The functional relationship between production cost and relative reserve-production ratio (RRPR) was derived by performing regressions on 1987-2000 data for production cost (PC) and RRPR (BP, 2007; DTI, 2007). Equations B.12-B.14 provide the regression results and indicate how PUC is computed:

$$
\begin{array}{cc}
\operatorname{Ln}(P C)= & 0.28-1.56 \operatorname{Ln}(R R P R) \\
& (0.036) \quad(0.134) \\
\mathrm{R}^{2}=.92 & \mathrm{SER}=.11
\end{array}
$$

\footnotetext{
${ }^{8}$ For eqn. B.6: T statistic is significant at the 1 per cent level and F statistic is significant at the 5 per cent level; For eqn. B.7: T statistic is significant at the 2.5 per cent level and F statistic is significant at the 5 per cent level
} 


$$
\begin{aligned}
& R R P R=\frac{R P R}{N R P R}=\frac{P R / P R R}{N R P R} \\
& P U C=\frac{I P C \times P C F}{P R R}
\end{aligned}
$$

RPR - Reserve-production ratio (Years)

PR - Proved reserves (Cubic meters)

PRR - Production rate (Cubic meters/year)

RRPR - Relative reserve-production ratio (Dimensionless)

NRPR - "Normal” reserve-production ratio (12 years)

PUC - Production unit cost (GBP/Cubic meter)

IPC - Initial production cost (£447 Million in 1987)

PCF - Production cost factor (Dimensionless)

In order to derive the functional relationship between return on investment (ROI) and investment in production (PSIP) a regression was performed on data for operating expenditures plus other costs related to production expansion and actual ROI. The result of this regression analysis is as follows ${ }^{9}$ :

$$
\begin{array}{cc}
\operatorname{Ln}(P S I P)= & 0.88 \operatorname{Ln}(R O I)-1.098 \\
& (0.24) \\
\mathrm{R}^{2}=.82 & \mathrm{SER}=.1
\end{array}
$$

Equations (B.16) and (B.17) show how the variable 'Desired Production Rate (DPR)' is obtained.

$$
\begin{aligned}
& D I P=P S I P \times(S R-I E \& A) \\
& D P R=\frac{D I P}{P U C}
\end{aligned}
$$

DIP - Desired investment in production (GBP/year)

PSIP - Percentage of sales revenue invested in production (\% per year)

$\mathrm{SR}$ - Sales revenue (GBP/year)

IE\&A - Investment in exploration and appraisal (GBP/year)

DPR - Desired production rate (Cubic meters/year)

PUC - Production unit cost (GBP /Cubic meter)

Functional relationship between price and relative reserve-demand ration (RRDR) is shown in (B.18) ${ }^{10}$.

$$
\begin{aligned}
& \operatorname{Ln}(P)=0.11-2.03 \operatorname{Ln}(R R D R) \\
& \mathrm{R}^{2}=.9 \quad(0.03) \quad \mathrm{SER}=.08
\end{aligned}
$$

\footnotetext{
${ }^{9}$ For eqn. B.15: T statistic and F statistic are significant at the 5 per cent level

${ }^{10}$ For eqn. B.18: $\mathrm{T}$ statistic and $\mathrm{F}$ statistic are significant at the 1 per cent level
} 
The price of gas (AWP) is defined as follows:

$$
\begin{gathered}
\text { TUC }=\text { COE \& A+PUC } \\
S T C=S M O O T H 3(T U C, S D) \\
A W P=P F \times S T C \\
\text { PF }- \text { Price factor (Dimensionless) }
\end{gathered}
$$

AWP - Average wholesale price (GBP/cubic meter)

TUC - Total unit cost (GBP/cubic meter)

COE\&A - Cost of exploration and appraisal (GBP/cubic meter)

PUC - Production unit cost (GBP/cubic meter)

STC - Smoothed total cost (GBP/cubic meter)

SMOOTH3 - Third-order exponential smoothing function

SD - Smoothing delay (Years)

A delay in TUC is introduced (as indicated by B.20) because of the heterogeneous nature of the costs of gas. At the initial stage of a field's development, gas is produced at lower prices than at later stages (because of the depletion effect on costs) (Naill, 1973). The length of the smoothing delay (SD) depends on the magnitude of the discovery and the production rate. New discoveries lead to depletion and hence increase the cost of future discovered gas. To reflect the increase in the cost of that particular amount of discovered gas the delay time should equal the RPR. When new discoveries exceed the production rate, RPR will increase and therefore, the cost of that particular amount of discovered gas will be high only after a period of time indicated by RPR.

To validate the assumption regarding the relationship between price and consumption rate a regression was performed on 1987-2005 data for average gas price and consumption rate (BP, 2007; DTI, 2007). We included a time variable in the regression to account for other effects on gas consumption, such as income effect. The regression ${ }^{11}$ yielded:

$$
\begin{gathered}
\operatorname{Ln}(C)=2.56-0.42 \operatorname{Ln}(P)+0.054(t) \\
(0.41) \quad(0.13) \quad(0.004) \\
\mathrm{R}^{2}=.945 \quad \mathrm{SER}=.063
\end{gathered}
$$

(B.23) shows how consumption rate is derived.

$$
C R=C F \times N G D
$$

$\mathrm{CR}$ - Consumption rate (Cubic meters/year)

\footnotetext{
${ }^{11}$ For eqn B.22: T statistics and F statistic are significant at the 1 per cent level
} 
$\mathrm{CF}$ - Consumption factor (Dimensionless)

NGD - Natural gas demand (Cubic meters/year)

Production rate is derived as follows:

$P R R=\min (D P R, C R)$

PRR - Production rate (Cubic meters/year)

DPR - Desired production rate (Cubic meters/year)

$\mathrm{CR}$ - Consumption rate (Cubic meters/year)

\section{Demand projection and substitution sector}

Equations $^{12}$ (B.25-B.28) show the result of regressions performed on 1976-2005 data for average gas price, coal, oil, nuclear and hydro energy demand.

$$
\begin{aligned}
& \operatorname{Ln}(C S)=0.206 \operatorname{Ln}(P)-0.046(t)-0.001 \\
& \begin{array}{lll}
(0.049) \quad(0.004) \quad(0.21)
\end{array} \\
& { }^{2}=.917 \quad \mathrm{SER}=.089 \\
& \operatorname{Ln}(O S)=-0.036 \operatorname{Ln}(P)-0.004(t)-1 \\
& (0.025) \quad(0.002)(0.11) \\
& \mathrm{R}^{2}=.64 \quad \mathrm{SER}=.046 \\
& \operatorname{Ln}(N S)=0.227 \operatorname{Ln}(P)+0.017(t)-2.19 \\
& (0.069) \quad(0.005)(0.3) \\
& \mathrm{R}^{2}=.845 \quad \mathrm{SER}=.12 \\
& \operatorname{Ln}(H S)=0.151 \operatorname{Ln}(P)-0.005(t)-4.4 \\
& \begin{array}{lll}
(0.067) \quad(0.005) & (0.29)
\end{array} \\
& \mathrm{R}^{2}=.25 \quad \mathrm{SER}=.12
\end{aligned}
$$

The calculation of gas demand is as follows:

$$
\begin{aligned}
& N G D=G S T P E D \times T P E D \\
& T P E D=I T P E D \times \exp ^{T \times T P E D G R} \\
& G S T P E D=1-(C S+O S+N S+H S) \\
& C S=C S F \times I C S \times \exp ^{T \times C S G R} \\
& O S=I O S \times \exp ^{T \times O S G R}
\end{aligned}
$$

\footnotetext{
${ }^{12}$ For eqn. B.25: T statistics and F statistic are significant at the 1 per cent level. For eqn. B.26: T statistics are significant at the $10 \%$ level and F statistic is significant at the 1 per cent level. For eqn. B.27: T statistics and F statistic are significant at the 1 per cent level. For eqn. B.28: T statistic for price coefficient is significant at the $1 \%$ level; T statistic for time coefficient is insignificant; F statistic is significant at the 5 per cent level
} 


$$
\begin{aligned}
& N S=N S F \times I N S \times \exp ^{T \times N S G R} \\
& H S=I H S \times \exp ^{T \times H S G R}
\end{aligned}
$$

NGD - Natural gas demand (Cubic meters/Year)

GSTPED - Gas share in total primary energy demand (Cubic meters/Year)

TPED - Total primary energy demand (MTOE/year)

ITPED - Initial total primary energy demand (207.4 MTOE or 230.4 BCM in 1987)

TPEDGR - TPED growth rate (\% per year)

CS - Coal share in TPED (\%)

CSF - Coal substitution factor (Dimensionless)

ICS - Initial coal share in TPED (35.5\% in 1987)

CSGR - Coal share growth rate (\% per year)

OS - Oil share in TPED (\%)

IOS - Initial oil share in TPED (36.3\% in 1987$)$

OSGR - Oil share growth rate is exogenously determined at $-0.67 \%$ per year ${ }^{13}$

NS - Nuclear share in TPED (\%)

NSF - Nuclear substitution factor (Dimensionless)

INS - Initial nuclear share in TPED $(6.02 \%$ in 1987$)$

NSGR - Nuclear share growth rate (\% per year)

HS - Hydro share in TPED (\%)

IHS - Initial hydro share in TPED $(0.675 \%$ in 1987$)$

HSGR - Hydro share growth rate is exogenously determined at $0.49 \%$ per year $^{14}$

$\mathrm{T}$ - Time (years)

\footnotetext{
${ }^{13}$ Based on data from 1976-2005 average oil demand in TPED exhibited a decline of 0.67\% per year (DTI, 2006b)

${ }^{14}$ Based on data from 1976-2005 average hydro energy demand in TPED grew at $0.49 \%$ per year (DTI, 2006b)
} 